\title{
An Exploratory Randomized Controlled Trial of Personalized Lifestyle Advice and Tandem Skydives as a Means to Reduce Anhedonia
}

\author{
Eeske Van Roekel \\ Charlotte Vrijen \\ Vera E. Heininga \\ Maurits Masselink \\ Elisabeth $\mathrm{H}$. Bos \\ Albertine J. Oldehinkel \\ University of Groningen, University Medical Center Groningen
}

\begin{abstract}
Anhedonia is a major public health concern and has proven particularly difficult to counteract. It has been hypothesized that anhedonia can be deterred by engagement in rewarding social and physical events. The aims of the present study were to examine (1) the effects of personalized lifestyle advice based on observed individual patterns of lifestyle factors and experienced pleasure in anhedonic young adults; and (2) whether a tandem skydive can enhance the motivation to carry out the recommended lifestyle changes. Participants $\left(N=69 ; M_{\mathrm{age}}=21.5, S D=2.0 ; 79.7 \%\right.$ female $)$ were selected through an online screening survey among young adults. Inclusion criteria were persistent anhedonia and willingness to perform a tandem skydive. Participants filled out questionnaires on their smartphones for 2 consecutive months ( 3 times per day). After the first month, they
\end{abstract}

Research reported in this publication was supported by a Vici grant (016.001/002) from the Netherlands Organization for Scientific Research to Albertine J. Oldehinkel. We would like to specifically thank Ando Emerencia and Rob Wanders for their help with the analyses and graphical representations, Tom Bak for coordinating all data collection activities, and Sanne van der Ploeg, Grejanne Dijkstra, and Nicole Snippen for their assistance in data collection.

Address correspondence to Eeske Van Roekel, University of Groningen, University Medical Center Groningen, Interdisciplinary Center Psychopathology and Emotion regulation, CC 72, P.O. Box 30001, 9700 RB Groningen, the Netherlands; e-mail: g.h.van.roekel@umcg.nl.

0005-7894/@ 2016 Association for Behavioral and Cognitive Therapies. Published by Elsevier Ltd. All rights reserved. were randomly assigned to one of three groups: (1) no intervention, (2) lifestyle advice, and (3) lifestyle advice and tandem skydive. The momentary questionnaire data were analyzed using interrupted time series analyses (ITSA) in a multilevel model and monthly pleasure and depression questionnaires by repeated measures ANOVA. No group differences were found in monthly depression and pleasure scores, but the momentary data showed higher positive affect (PA) and pleasure ratings in the month following the intervention in the two intervention groups than in the control group. The tandem skydive did not have any effects above the effects of the lifestyle advice. Our results indicate that providing personalized lifestyle advice to anhedonic young adults can be an effective way to increase PA and pleasure.

Keywords: loss of pleasure; anhedonia; ecological momentary intervention; lifestyle advice; tandem skydive

ANHEDONIA IS DEFINED AS diminished interest or pleasure in activities that were experienced as pleasurable before (i.e., a loss of pleasure; American Psychiatric Association, 2013). Anhedonia is common among adolescents and young adults and has debilitating consequences, such as a longer and more severe course of depression (Wilcox \& Anthony, 2004) and increased risk for suicide (Nock \& Kazdin, 2002). Anhedonia can have particularly negative consequences in young adulthood (Gabbay et al., 
2015; Kupferberg, Bicks, \& Hasler, 2016), as this is a period in which life course decisions are made based on what is satisfying or enjoyable. Despite its detrimental effects, anhedonia has proven particularly difficult to treat (Fusar-Poli et al., 2015; Treadway \& Zald, 2011; Wykes, Steel, Everitt, \& Tarrier, 2008) and is the symptom that often remains when other symptoms have disappeared (Gutkovich et al., 2010). Further, there is a lack of treatments targeting anhedonia specifically. Hence, there is a need for effective interventions to help anhedonic individuals regain pleasure. In the present study, we aimed to explore whether anhedonia can be deterred by providing anhedonic young adults with personalized lifestyle advice.

Anhedonia is a transdiagnostic symptom that is present in multiple diagnostic categories, such as depression, bipolar disorder, and schizophrenia (American Psychiatric Association, 2013). The few studies that have examined interventions to reduce anhedonia so far have focused particularly on individuals with schizophrenia (Favrod et al., 2015; Favrod, Giuliani, Ernst, \& Bonsack, 2010) or depression (Kramer et al., 2014). To our knowledge, two interventions have been developed to target anhedonia in schizophrenic patients: the Anticipatory Pleasure Skills Training (APST; Favrod et al., 2010) and the Positive Emotions Program for Schizophrenia (PEPS; Favrod et al., 2015). APST is a cognitivesensory intervention aimed at increasing anticipatory pleasure, which consists of 10-25 hours of training. PEPS is a group therapy consisting of eight 1-hour sessions, focused on increasing the anticipation and maintenance of positive emotions. Both interventions have shown positive results in small samples $(N=5$ for APST; $N=31$ for PEPS), but have not yet been tested in randomized controlled trials (RCT). For depression, treatment often starts with behavioral activation (BA) treatment (Kanter et al., 2010) to stimulate depressed patients to participate in rewarding activities. In $\mathrm{BA}$, the therapist and patient decide together which activities are experienced as pleasurable, and the patient is stimulated to set goals to reengage in these pleasurable activities. BA has been found to be effective in reducing depressive symptoms (Cuijpers, van Straten, \& Warmerdam, 2007) and in reducing depressive symptoms and manic symptoms in bipolar disorder in a first explorative study (Weinstock, Melvin, Munroe, \& Miller, 2016). These interventions are all fairly time-consuming, in that they consist of multiple sessions and require a trained psychologist to deliver the interventions. Furthermore, although activity scheduling is part of BA treatments and the PEPS intervention, these treatments lack a thorough and objective analysis of pleasurable experiences. This is important, as anhedonia is characterized by difficulties recalling pleasurable experiences (Lepage, Sergerie, Pelletier, \& Harvey, 2007), and therefore, anhedonic individuals may not be able to recall all activities that they enjoy.

Because of rapid technological developments, it is now possible to overcome these issues by using momentary assessments to provide individuals with insight in their daily life emotions and activities (Myin-Germeys, Klippel, Steinhart, \& Reininghaus, 2016; Wichers et al., 2011). A main advantage of momentary assessments is their high ecological validity, as participants report on their mood and activities while they are living their daily lives (MyinGermeys et al., 2009). Up to now, only one study has used momentary assessments to provide depressed individuals with personalized feedback on the situations in which they experience positive affect (PA) (Kramer et al., 2014). In this study, participants received weekly reports that showed how much PA they experienced in different contexts and during different activities. Importantly, no concrete advice was provided to participants, and the presented feedback was purely descriptive (i.e., the associations were not tested). Although no direct effects were found on momentary ratings of PA (Hartmann et al., 2015), individuals receiving the personalized feedback did decrease more in depressive symptoms on follow-up assessments than individuals who did not receive the feedback (Kramer et al., 2014). The authors did not explore how the personalized feedback affected anhedonia specifically. Whereas these results are very promising, the intervention could be taken one step further, by not only showing participants in which situations and environments they experienced PA, as Kramer et al. (2014) did, but also providing concrete suggestions regarding how they could change their lifestyle. In the present study, we aim to provide anhedonic young adults with personalized advice on which lifestyle factors (e.g., physical exercise) they can change to experience more pleasure, based on observed individual patterns of lifestyle factors and experienced pleasure.

However, even when tailor-made and concrete, lifestyle changes are likely hard to accomplish for anhedonic individuals, as anhedonia is often characterized by a lack of drive to pursue rewarding activities (Treadway, Bossaller, Shelton, \& Zald, 2012; Treadway \& Zald, 2011). An intense experience that will elicit strong positive responses in all individuals may be necessary to break this vicious circle of low pleasure and motivation, and to reboot the reward system (Grillo, 2016). A freefall experience such as skydiving may be an acceptable and effective human model to accomplish this goal (Chatterton, Vogelsong, Lu, \& Hudgens, 
1997), as such an extreme thrill is likely to provide a shock to the reward system and could potentially reset the way individuals respond to their environment. Given the lack of research on this particular topic, it is hard to predict what the precise mechanism is through which a free-fall experience could increase pleasure and motivation. However, the hypothesis that such a shock could provide improvements in mood is very similar to the hypothesis that mood can be improved by means of electroconvulsive therapy (ECT), which is currently still one of the most effective interventions for treating severe depressed patients and has been found to improve mood and anhedonia (American Psychiatric Association, 2008; Anderson \& Fergusson, 2013; Taylor, 2007).

Research in healthy individuals has shown that skydiving provokes strong emotions and physiological responses. Even though it is considered to be safe, falling from a great height evokes a substantial fight-flight response in virtually all individuals (Hare, Wetherell, \& Smith, 2013). Physiologically, skydiving results in increases in heart rate, blood pressure, and alpha-amylase and cortisol levels (Chatterton et al., 1997; Hare et al., 2013; Meyer et al., 2015). Psychologically, individuals experience extreme fear before and during the free-fall experience (Hare et al., 2013), followed by euphoria afterwards (Meyer et al., 2015). This contrast in emotions can be explained by Solomon's opponent process theory of acquired motivation (Solomon, 1980), which states that humans automatically contrast extreme emotions, such as fear and euphoria.

In addition to these immediate increases in mood in human studies, animal research has provided additional evidence for why a free-fall experience may boost the reward system (Wang \& Tsien, 2011). Mice who experienced a free fall showed increased firing of dopamine neurons in the ventral tegmental area in the brain, which is associated with rewardrelated motivation. Altogether, these findings indicate that free-fall experiences could increase positive affect and motivation, and so set an excellent stage for implementing lifestyle advice that promote more persistent positive feelings.

\section{THE PRESENT STUDY}

The first aim of this exploratory study was to examine whether personalized lifestyle advice, based on observed patterns of pleasure and lifestyle factors, can increase pleasure and PA and decrease depressive symptoms and negative affect (NA) in anhedonic young adults. Secondly, we explored the provoking idea that a free fall may foster the implementation of the lifestyle advice, by testing whether lifestyle advice combined with a tandem skydive had a more positive effect than lifestyle advice only. In order to explore whether a free fall might be effective, we chose to investigate its most extreme form, i.e., a tandem skydive, to rule out the possibility that negative findings were due to the experience being not intense enough. This part of the study was a proof-of-concept, to explore the potential effects of skydiving. We investigated both questions in a sample of 69 anhedonic adults, who were randomly assigned to a control group receiving no intervention $(N=22)$, a group who received lifestyle advice $(N=22)$, or a group who received both lifestyle advice and a tandem skydive $(N=25)$. As effects at the group level do not necessarily apply to each individual, we conducted both group-level and individual-level analyses, to further explore whether the intervention may be effective for specific individuals. In contrast to sex differences in depressive symptoms in general and depressed mood specifically (Hankin \& Abramson, 2001), levels of anhedonia do not differ between males and females (Bennik, Nederhof, Ormel, \& Oldehinkel, 2014; van Roekel et al., 2015). Previous research was inconclusive about whether the effects of personalized feedback showed sex differences (Kramer et al., 2014). To exclude confounding by possible sex differences, we selected an equal number of males and females in each intervention group.

\section{PARTICIPANTS}

\section{Methods}

Participants were selected through an online screening survey among 2,937 young adults $(M$ age = 21.4 years, $S D=1.9,78 \%$ female) from the northern part of the Netherlands. Inclusion criteria were persistent anhedonia and willingness to perform a skydive. Persistent anhedonia was defined as a pleasure level below the $25^{\text {th }}$ percentile, which was experienced as lower than normal, and lasted for at least 2 months. Hence, the criteria involved not only a low level of pleasure, but also that this low pleasure level was considered egodystonic and unlikely to be transient. These criteria were assessed by means of three items from the Domains of Pleasure Scale (DOPS); Masselink et al., submitted), which assess (a) level of pleasure in the past 2 weeks, (b) whether this level represents a change compared to what is considered normal for this individual, and (c) the duration of the loss of pleasure, if any. Exclusion criteria were inability to keep an electronic diary three times a day; current professional treatment for psychiatric problems; use of psychotropic medication; epilepsy; pregnancy; conditions that obstruct participating in a tandem skydive (i.e., loose prostheses; height of more than 2 meters; weight of more than $95 \mathrm{~kg}$; inability to raise one's legs 90 degrees; 
cardiovascular complaints or problems; and significant visual or hearing impairments); and experience with skydiving, bungee jumping, or base jumping. We aimed for 20 participants in each intervention group (i.e., 60 in total). Because we anticipated some dropout, we decided to include 4 extra participants in each group (i.e., 72 in total).

For multilevel modeling, a minimum number of 50 Level 2 cases and 20 Level 1 cases is sufficient to accurately estimate regression coefficients and variances (Hox, 2002). As we included over 60 individuals (Level 2) and 180 momentary assessments (Level 1), we considered the power to be adequate to examine our main research question. For the repeated monthly measures, we conducted a post-hoc power analysis in Stata (StataCorp, 2013). Results showed that we needed 21 individuals per group $($ power $=0.8$, alpha $=0.05)$ to detect a large difference between groups (Cohen's $d=0.8$ ) with a correlation of 0.6 between the repeated assessments. Our smallest group consisted of $N=22$ participants; hence, it was determined that we had enough power to detect large differences between groups.

\section{PROCEDURE}

Participants were recruited in the northern part of the Netherlands through flyers, electronic learning environments, advertisements on social media, and invitations during lectures and classes. After subscribing on the study website (www.nofunnoglory.nl), participants received an email with the link to the online questionnaire. Participants received a gift card of 10 euro after completion of the questionnaire.

When participants fulfilled the inclusion and exclusion criteria in the screening survey and indicated willingness to participate in further research, they were contacted for the intervention study. They were sent an information letter and informed consent form by email. If they agreed to participate, they had to return the signed informed consent form by mail or email. When participants did not reply, they were sent a reminder or contacted by telephone. Upon receiving the signed informed consent form, participants were invited for an instruction session with one of our four team members, which took place at the University Medical Center Groningen. During this meeting, study staff verified whether participants met study criteria. All study procedures, including study materials, were explained to ensure participant comprehension. Furthermore, an appointment was made for the next meeting (i.e., intervention session), to be held approximately 1 month later. Please see Figure 1 for a flowchart of the study procedure.

Participants started with the daily electronic questionnaires within a few days after the instruction session $(M=1.97, S D=2.47$, range $0-13)$, depending on when the intervention session could be planned. If scheduling issues dictated that the intervention session had to be planned more than a month after the instruction session, the start of the daily questionnaires was postponed accordingly. The participants received three questionnaires per day, with fixed 6-hour intervals (e.g., 9:00 A.M., 3:00 P.M., 9:00 P.M.). The sampling scheme was determined in consultation with the participant. Each of the daily questionnaires was prompted by a text message containing a link to the online questionnaire. The questionnaires had to be filled out within 2 hours after the first notification; reminders were sent after 60 and 90 minutes. Completion of the questionnaire took around 3 minutes. Participants continued with the daily questionnaires for about 3 months in total. The first month was the baseline phase, which was used to generate the lifestyle report. Further, data from the baseline phase were compared with data from the second month, the intervention phase, which was used to examine effects of the interventions. Since we wanted to give all participants the

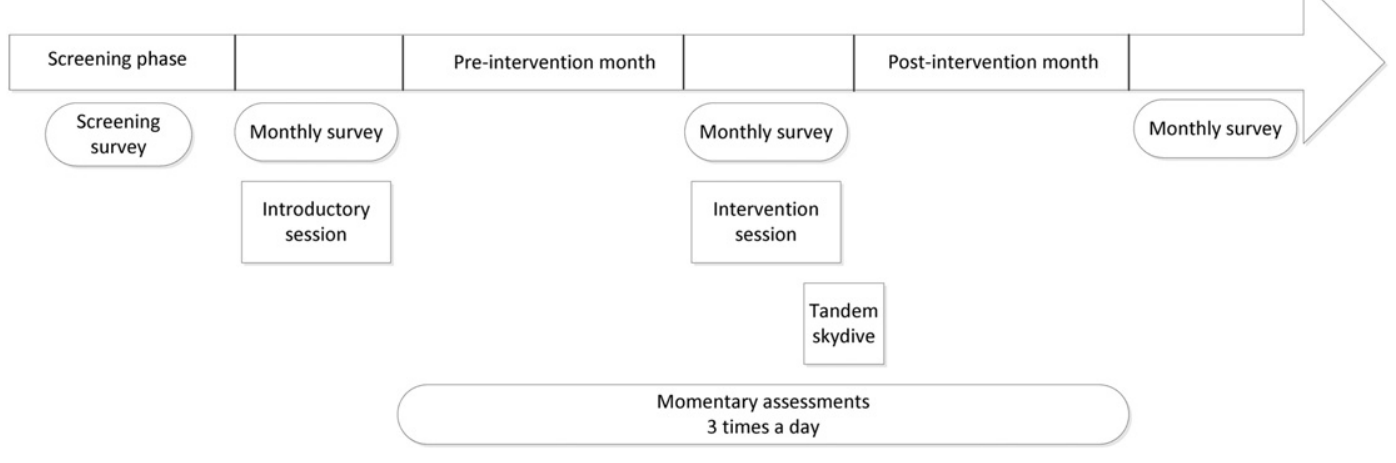

FIGURE I Flowchart of the study procedures. 
opportunity to receive the interventions, each participant was allowed to choose any intervention (that is, no intervention, lifestyle advice, lifestyle advice plus skydive) after the intervention phase. Because the randomization was compromised after the second month, only the data assessed before the free choice intervention were included in the present study (i.e., first 2 months of data). In general, the compliance was excellent, with an average percentage of missing assessments of only $7.6 \%$ (range $0.5 \%-22.9 \%$ ).

Intervention allocation was done in four rounds. We used block randomization for males and females separately with a block length of 6 blocks. Hence, the three interventions were equally distributed after each group of 6 males or females. The sequence of the interventions in each block was determined using an online random block generator (www.randomization.com), and this sequence was entered in a blinded Excel file. During each round, the ID numbers of the participants that needed to be assigned to an intervention were entered in this Excel file in a random order (i.e., order was determined based on an online random sequence generator, www.random.org). Participants received their intervention allocation through email 1 week before the intervention. When participants were assigned to the tandem skydive group, they were contacted by telephone to make an appointment for that. If possible, the skydive always took place in the weekend following the intervention session, at a nearby airport. During a 1.5 -hour individual meeting with one of the four team members (the intervention session), we discussed the progress with the participants as well as if a participant belonged to one of the two intervention groups, the lifestyle report and advice (see below for detailed description of the intervention). During the meeting at the end of the intervention month, we discussed the extent to which participants had been able to follow-up on each lifestyle advice.

In addition to the daily electronic questionnaires, participants filled out online questionnaires measuring consummatory pleasure and depressive symptoms on the day of the instruction session (i.e., start of the first month), one day before the intervention session (i.e., end of the first month), and at the end of the intervention month (i.e., end of second month). As participants already knew which intervention they would receive at the second monthly assessment and during the final week of momentary assessments before the intervention session, these assessments were not included in the final analyses.

Participants received a compensation of 75 euros after completion of the first month, 125 euros after the second month, and 250 euros after completion of the third month, providing that they filled out the monthly questionnaires, provided blood samples (i.e., this study was part of a larger study for which blood samples were included; see Van Roekel et al., 2016, for the complete study protocol), and completed more than $80 \%$ of the momentary assessments. The present study is registered in the Dutch Clinical Trial Register (NTR5498) and was approved by the Medical Ethical Committee from the University Medical Center Groningen (no. 2014/508).

\section{MEASURES}

Experience Sampling Method (ESM) Measures Used in the Lifestyle Reports

The ESM items used in the lifestyle reports were based on previous ESM studies (e.g., van der Krieke et al., 2015; van Roekel et al., 2015). The description of all ESM questions that were used to create a personalized lifestyle report for each individual can be found in Appendix A.

\section{Pleasure}

We used one item to measure pleasure: "I experienced pleasure since the last assessment." Participants were asked to rate the extent to which this statement was applicable by moving a slider along a continuum (i.e., Visual Analogue Scale; VAS) anchored with the words not at all on the left and very much on the right. The location of the slider was converted into a score between 0 and 100 .

\section{Positive Affect (PA)}

PA was measured with 10 items, namely, feeling interested, joyful, determined, calm, lively, enthusiastic, relaxed, cheerful, satisfied, and energetic. These items were rated on a similar VAS scale as described for pleasure (ranging from 0-100). The PA score was calculated by averaging the 10 item scores. Cronbach's alpha was .94 (calculated over all assessments).

\section{Negative Affect (NA)}

NA was measured with 8 items: upset, gloomy, sluggish, anxious, bored, irritated, nervous, and listless, rated on a similar VAS scale (ranging from 0-100) as used for pleasure and PA. NA was calculated by averaging the 8 item scores. Cronbach's alpha was .86 (calculated over all assessments).

\section{Consummatory Pleasure}

Consummatory pleasure was measured in the monthly questionnaires with the DOPS. This scale consists of 21 items, which represent different domains of pleasure experiences: perceptual pleasures (8 items, e.g., I enjoy a good meal, I enjoy pleasant smells), social pleasures (5 items, e.g., I enjoy having close friendships, I enjoy doing things with other people), sexual pleasures (3 items, e.g., I 
enjoy sex [alone or with someone else]), and pleasure of personal achievements (5 items, e.g., I enjoy getting better at something, I enjoy winning in games or sports). Participants rated on a VAS scale ranging from not at all to very much (0-100) how much they enjoyed the described experiences. In order to give each domain equal weight in the overall pleasure score, we first calculated mean scores for each domain, and subsequently averaged these means to create an overall consummatory pleasure score. The consummatory scale of the DOPS showed good convergent validity (Masselink et al., submitted). For the pre- and post-intervention assessments, respectively, Cronbach's alphas were .87 and .89 for perceptual pleasures, .89 and .89 for social pleasures, .85 and .91 for sexual pleasures, and .81 and .84 for pleasure of personal achievement.

\section{Depressive Symptoms}

We measured depressive symptoms with the 9-item Patient Health Questionnaire (PHQ-9; Kroenke, Spitzer, \& Williams, 2001). Participants rated the extent to which they experienced 9 different symptoms in the past 2 weeks on a scale ranging from not at all to almost every day. Sample items are "feeling down, depressed or hopeless," "feeling tired or having little energy." As one of the items overlapped with the pleasure scale (i.e., "little interest or pleasure in doing things"), we excluded this item from the scale and created a sum score based on 8 items. The PHQ-9 has obtained good construct and criterion validity in previous research (Kroenke et al., 2001). Cronbach's alpha was .83 for the pre-intervention assessment and .80 for the postintervention assessment.

\section{Psychiatric Problems}

We measured the prevalence of other psychiatric problems with the Adult Self-Report (ASR; Achenbach \& Rescorla, 2001), which consists of 123 items that are rated on a 3-point scale ranging from not at all to clearly/often. We used the DSM-IV-based scales for depressive problems (14 items; Cronbach's alpha $=.77$ ), anxiety problems (7 items; Cronbach's alpha $=.76$ ), avoidant personality problems (7 items; Cronbach's alpha $=.68$ ), ADHD problems (13 items; Cronbach's alpha = .78 ), and antisocial problems (20 items; Cronbach's alpha $=.67)$.

\section{Advice Adherence}

The information about advice adherence provided by participants in an interview at the end of the intervention phase was coded into an advice adherence variable, with 0 representing not at all, 1 representing to some extent, and 2 representing to a large extent.

\section{INTERVENTIONS}

Lifestyle Advice

The lifestyle advice was based on the first 30 days of ESM measurements (i.e., baseline phase; 90 assessments in total). Participants received a lifestyle report, which consisted of four main parts: (1) descriptive information, (2) comparison with norm groups, (3) personal networks, and (4) the advice. The specifics of the variables used in the lifestyle report can be found in Table A1. All variables were used to construct personal networks, which were based on Autoregressive moving average (ARMA) analyses and automated Vector Autoregressive modeling (VAR; Brandt \& Williams, 2007; Autovar: Emerencia et al., 2015). Pleasure, social context, and activities were additionally used for descriptive purposes, and part of the activities and substance use were used for comparisons with norm groups. See Appendix B for a detailed description of the procedure of the lifestyle advice, the conducted analyses, and the content of the lifestyle report.

Based on the data collected during the baseline phase, potential advice was formulated. Because the personal networks provided information about statistically significant associations between pleasure and lifestyle factors, advice based on these networks were preferred. If no, or an insufficient number of, significant results were found, further advice were based on (a) infrequent lifestyle factors that could not be tested in the analyses, but were experienced as pleasurable according to the descriptive information, or (b) lifestyle factors with a frequency that deviated from the norm group. During the intervention session, the information in the lifestyle reports was explained to and discussed with the participants and they received a paper version of the report to take home, without the lifestyle advice. We checked whether the participants recognized themselves in the presented results and asked them to reflect on the results. Finally, we discussed the potential lifestyle advice with the participant, and decided together with the participants which recommendations were feasible and which were not. For the final advice, we came to an agreement with participants as to how often and when they were going to perform the suggested activities. Each participant received advice about two or three lifestyle factors. After the intervention session, the concept advice was reformulated when needed and final versions were sent to participants through email.

In total, 39 recommendations concerned social activities (e.g., plan more social activities with friends or family), 19 physical activity, 13 physical activity in combination with spending time outside, 20 worrying (e.g., mindfulness exercises), 5 going 
outside, 10 hobbies, 4 sleep rhythm, 9 time spent on television, Internet, or social media, and 2 soft drugs (e.g., cannabis).

\section{Tandem Skydive}

The tandem skydive took place at the certified skydive center, "Eelde-Hoogeveen," the weekend following the intervention session. In case of bad weather (i.e., rain or hard wind), the skydive was rescheduled, if possible in the same weekend or 1 week later. The average number of days between the intervention session and the skydive was 5.5 ( $S D=5.5$, range 1-27 days). After arrival at the skydive center and around 15 minutes before the skydive, the participants received instructions from the skydive instructors. Participants exited a small turbine-powered aircraft (i.e., Cessna 207), at a height of 10,000 feet, safely attached to the tandem skydive instructor. The free fall lasted for around 30 to 40 seconds, the total skydive around 5 minutes.

\section{ANALYSES}

A randomization check was performed by comparing the intervention groups with regard to educational level (chi-square tests), age, and preintervention levels of pleasure and depression (ANOVAs). To examine the effects on the momentarily assessed outcomes (i.e., pleasure, PA, and NA), we used multilevel analyses in Mplus version 7.4 (Muthén \& Muthén, 1998). As we had at least 30 days of data (i.e., 90 assessments) before the intervention (i.e., baseline phase) and at least 30 days of data after the intervention (i.e., intervention phase), we used interrupted time series analyses (ITSA) to explore intervention effects (Huitema \& Mckean, 2000). In ITSA, it is possible to explore changes in outcomes between the baseline phase and the intervention phase. Further, an important advantage of ITSA is that it is possible to explore whether changes in the outcome variables are due to trends that were already present in the baseline phase. In the first step, we examined whether the level of pleasure differed between the baseline and intervention phase. We examined the difference in mean level between both phases (i.e., level change) by adding a dummy variable for the phase to the model (i.e., baseline phase versus intervention phase) as a random effect. We modeled the interaction between group ( 0 for control group, 1 for both intervention groups) and phase to investigate whether the mean scores of the intervention groups had changed more than those of the control group after the intervention.

In the next step, we checked whether this change was gradual or abrupt and whether change was already present in the baseline phase by including time trends in the model, following recommendations by Huitema and McKean (2000). By estimating both the linear change in the baseline phase (i.e., slope), the change in this slope in the intervention phase (i.e., slope change), and the interaction between these time trends and group, we examined whether participants differed in the extent to which they gradually changed in their affect levels and whether this gradual change was already present in the baseline phase. Please note that the estimate for level change in this model no longer represents the change in mean level after the intervention, but the change in mean affect immediately after the intervention was provided. These analyses were repeated for PA and NA. We first compared the control group with both intervention groups, and subsequently examined differences between the lifestyle advice only group and the tandem skydive group. If significant group differences were found (i.e., significant cross-level interactions), we calculated the proportion of variance in the coefficient for level change that was explained by the crosslevel interaction following guidelines by Aguinis, Gottfredson, and Culpepper (2013).

In case of significant between-individual differences in level estimates (i.e., significant random variance in the coefficient for the level change), we further examined individual differences in level change by fitting ITSA models for each individual and each outcome variable separately. We used the same design specifications as above (Huitema \& McKean, 2000). The individual time-series analyses were controlled for autocorrelation by fitting Auto Regressive Moving Average (ARMA) models to the residuals (Hartmann et al., 1980). Dummy variables for time of day (i.e., afternoon and evening) were included in each model to adjust for daily cycles. When the model fit was acceptable, we added the dummy variable for level change as a predictor in the model. The estimates for this predictor in the final models were saved. Part of these analyses (i.e., 25\%) were repeated by another team member to check consistency of the modelbuilding process. In order to visualize the individual level change estimates, we created forest plots for each outcome variable separately. To compare whether individual characteristics (i.e., gender, severity of pleasure loss, duration of pleasure loss, advice adherence) were associated with the extent to which individuals improved, we conducted regression analyses or ANOVA (i.e., advice adherence) with the standardized level change estimates as outcome variables.

We further examined the effectiveness of the intervention by conducting repeated measures ANOVAs 
on the pre- and post-intervention assessments of pleasure and depressive symptoms. This was done in two steps: first we checked whether the two groups that received lifestyle advice differed from the control group. Second, we further compared the tandem skydive group with the lifestyle advice only group.

Effect sizes were calculated for all analyses. For the momentary data, we calculated Cohen's $d$ following the formula as suggested by Cohen (1988), dividing the mean group difference by the pooled pre-intervention $S D$. For the mean difference between groups, we included the estimated difference in level effects between the control group and the intervention groups. To calculate the preintervention pooled $S D$, we first calculated mean levels of the outcome measure (pleasure, PA, and $\mathrm{NA}$, respectively) in the pre-intervention month per individual. Subsequently, we calculated the SD over these within-person mean levels in both intervention groups. In this way, the pooled SD reflects the between-person variation in the outcome measures. For the monthly assessments, we used the formula as suggested by Morris (2008), using the pooled pre-intervention SD.

\section{Results}

PARTICIPANT FLOW

In total, 71 participants started with the momentary assessments (see Figure 2 for a flowchart). Two participants dropped out from the study: one due

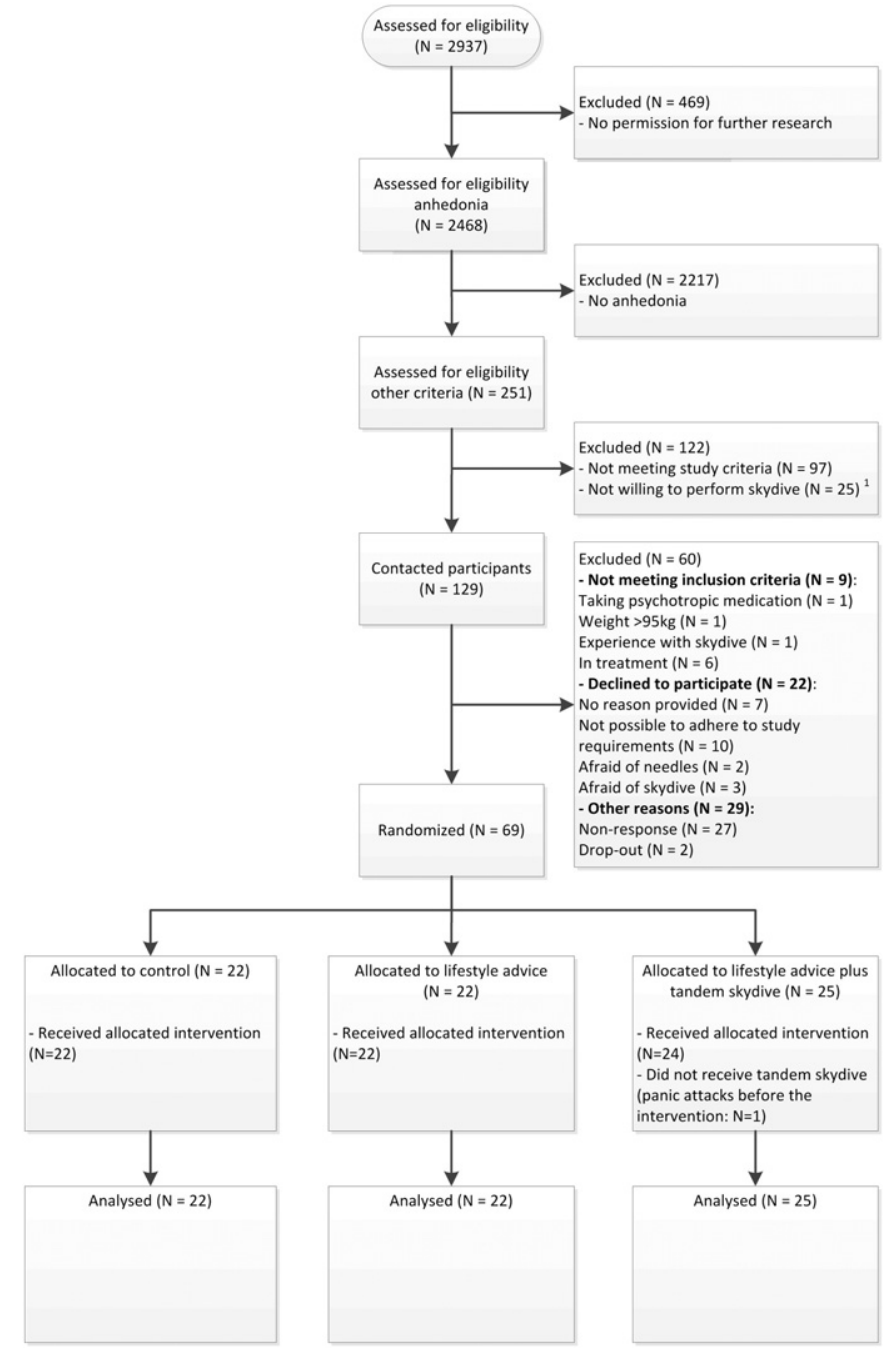

FIGURE 2 Flowchart of the participant enrollment. ' We checked whether the group who was not willing to perform a skydive $(N=25)$ differed from the group who was willing to perform a skydive (answer yes or maybe), and found no significant differences between these groups on the severity of anhedonia $(t=1.30, p=.13)$, the level of consummatory pleasure $(t=-0.84, p=.40)$ or depressive symptoms $(t=0.30, p=.77)$. 
to problems with mobile data subscription and another because she stopped filling out the momentary assessments. One participant did not partake in the skydive due to the possibility of panic attacks related to skydiving. She only received the lifestyle advice but was maintained in the tandem skydive group in the analyses, in line with the intentionto-treat principle. Finally, one person from the lifestyle advice only group was removed from the momentary data analyses as she reported that she had changed her interpretation of the questions with regard to pleasure and PA after the intervention session, which thwarted comparison of data from the baseline and intervention phase. This resulted in a final sample of 69 participants for inclusion in the monthly data analyses and 68 participants (22 no intervention, 21 lifestyle advice, 25 lifestyle advice plus tandem skydive) in the momentary data analyses. The number of assessments in the baseline phase ranged between 60 and $135(M=84.5, S D=12.9)$, the number of assessments in the intervention phase ranged between 69 and 165 assessments $(M=107.7$, $S D=15.8)$.

\section{DESCRIPTIVE STATISTICS}

Because we were interested in how knowledge about intervention allocation affected participants in the different intervention groups, we conducted additional analyses in which we compared the first 3 weeks of momentary assessments with the final week before the intervention session, and the second monthly assessment with the first monthly assessment. Paired samples $t$-tests showed that aggregated levels of pleasure, PA, and NA did not differ between the first 3 weeks and the final week of the baseline period in the no intervention group and in the tandem skydive group $(p>.05)$. For the lifestyle advice group, mean levels of PA, $t(21)=-3.30, p=$ .003 , were significantly higher and mean levels of $\mathrm{NA}, t(21)=3.72, p=.001$, significantly lower in the final week, compared to the first 3 weeks. For the monthly assessments, paired samples $t$-tests indicated that levels of consummatory pleasure and depressive symptoms did not differ between the preintervention assessment and the assessment before the intervention session in any of the intervention groups $(p>.05)$.

Descriptive statistics for each intervention group are presented in Table 1. As educational level may affect the extent to which different activities are enjoyed (e.g., intellectual activities), we checked whether educational levels were equally distributed over the three intervention groups, which was the case, $\chi^{2}(6)=5.65, p=.46$. Further, no significant differences were found in age, $F(2)=.58, p=.56$, baseline scores of pleasure, $F(2)=.12, p=.88$, or depressive symptoms, $F(2)=.27, p=.76$, between the three intervention groups. The majority of the participants experienced at least mild depressive symptoms as measured by the PHQ-9 (minimal symptoms: $N=6$; mild symptoms: $N=28$; moderate symptoms: $N=19$; moderately severe symptoms: $N=11$; severe symptoms: $N=5$ ), indicating that we

Table 1

Descriptive Statistics for the Three Intervention Groups

\begin{tabular}{|c|c|c|c|}
\hline & $\begin{array}{l}\text { No intervention } \\
(\mathrm{N}=22)\end{array}$ & $\begin{array}{l}\text { Lifestyle advice } \\
(\mathrm{N}=22)\end{array}$ & $\begin{array}{l}\text { Lifestyle advice and skydive } \\
(\mathrm{N}=25)\end{array}$ \\
\hline Females (\%) & 81.8 & 77.3 & 80.0 \\
\hline Age (M [SD]) & $21.4(2.0)$ & $21.3(2.0)$ & $21.9(2.0)$ \\
\hline \multicolumn{4}{|l|}{ Current education (\%) } \\
\hline Intermediate vocational education & 0.0 & 0.0 & 4.0 \\
\hline Higher secondary education & 4.6 & 0.0 & 0.0 \\
\hline Higher vocational education & 45.5 & 36.4 & 24.0 \\
\hline University & 50.0 & 63.6 & 60.0 \\
\hline None & 0.0 & 0.0 & $12.0^{\mathrm{a}}$ \\
\hline \multicolumn{4}{|l|}{ Ethnicity (\%) } \\
\hline Caucasian & 95.5 & 90.9 & 96.0 \\
\hline Latin-American & 4.6 & 0.0 & 0.0 \\
\hline Mixed African American/Caucasian & 0.0 & 4.6 & 4.0 \\
\hline Asian & 0.0 & 4.6 & 0.0 \\
\hline Consummatory pleasure pre-intervention & $58.84(12.75)$ & $60.42(9.62)$ & $59.72(9.12)$ \\
\hline Consummatory pleasure post-intervention & $56.49(14.72)$ & $61.41(9.70)$ & $58.08(11.92)$ \\
\hline Depressive symptoms pre-intervention & $7.91(3.62)$ & $8.55(4.23)$ & $7.76(3.62)$ \\
\hline Depressive symptoms post-intervention & $6.86(4.06)$ & $5.73(3.27)$ & $6.52(3.99)$ \\
\hline
\end{tabular}

Note. ${ }^{a}$ The highest levels of education attained for the three participants who currently did not follow education were applied university, intermediate vocational education, and lower secondary education. 
PERSONALIZED LIFESTYLE ADVICE AND TANDEM SKYDIVES TO REDUCE ANHEDONIA 85

Table 2

Differences in Estimates of Level and Slope Changes in Pleasure, PA, and NA, Between Control and Intervention Groups

\begin{tabular}{|c|c|c|c|c|}
\hline & \multicolumn{2}{|c|}{ Only level estimate } & \multicolumn{2}{|l|}{ Complete model } \\
\hline & $\begin{array}{l}\text { No Intervention } \\
(\mathrm{N}=22)\end{array}$ & $\begin{array}{l}\text { Intervention } \\
(N=46)\end{array}$ & $\begin{array}{l}\text { No Intervention } \\
(\mathrm{N}=22)\end{array}$ & $\begin{array}{l}\text { Intervention } \\
(\mathrm{N}=46)\end{array}$ \\
\hline Pleasure intercept & $53.65(2.29)$ & $53.57(1.26)$ & $56.43(2.19)$ & $54.12(1.18)$ \\
\hline Pleasure level estimate & $-1.82(1.34)^{*}$ & $2.58(1.09)^{\star}$ & $1.27(2.18)$ & $4.83(1.45)$ \\
\hline Pleasure slope baseline phase & & & $-0.07(0.03)$ & $-0.01(0.02)$ \\
\hline Pleasure slope change & & & $0.06(0.03)$ & $-0.02(0.02)$ \\
\hline PA intercept & $53.65(2.21)$ & $53.10(1.25)$ & $53.10(2.12)$ & $50.45(1.22)$ \\
\hline PA level estimate & $-0.03(1.01)^{\star \star \star}$ & $4.75(0.92)^{\star \star \star}$ & $-0.42(1.90)$ & $2.94(1.00)$ \\
\hline PA slope baseline phase & & & $0.02(0.03)$ & $0.06(0.02)$ \\
\hline PA slope change & & & $-0.02(0.03)$ & $-0.08(0.02)$ \\
\hline NA intercept & $23.15(1.76)$ & $24.53(1.30)$ & 25.68 (1.99) & $28.27(1.53)$ \\
\hline NA level estimate & $-2.47(1.18)$ & $-4.68(0.77)$ & $-0.20(1.45)$ & $-1.28(0.69)$ \\
\hline NA slope baseline phase & & & $-0.06(0.03)$ & $-0.09(0.02)$ \\
\hline NA slope change & & & $0.07(0.03)$ & $0.10(0.03)$ \\
\hline
\end{tabular}

Note. PA = Positive Affect, NA = Negative Affect.

${ }^{*} p<.05,{ }^{* *} p<.01,{ }^{* *} p<.001$. Please note that the reported significance levels indicate whether the difference between groups (i.e., the interaction) was significant. To calculate the slope in the intervention phase, the coefficients for the slope in the baseline phase and the slope change should be summed.

selected a group that experienced significant depressive symptoms in addition to anhedonia. With regard to the prevalence of other psychiatric problems, $7.2 \%$ fall in to the clinical range for anxiety problems, $18.8 \%$ fall into the clinical range for avoidant personality, and $11.6 \%$ into the clinical range for $\mathrm{ADHD}$ (see Appendix C).

\section{GROUP LEVEL ANALYSES MOMENTARY DATA}

The results of the group-level analyses of pleasure, PA, and NA can be found in Table 2. In the first models that included only the differences in level between the baseline phase and intervention phase, a significant interaction was found between group and phase for pleasure and PA. The intervention group showed an increase in pleasure and PA after the intervention session, whereas the control group showed no differences in affect level between the two phases. This finding indicates that, on average, participants in the intervention groups experienced higher pleasure and PA in the intervention phase compared to the baseline phase, whereas those in the control group did not. The proportion of random effect variance accounted for by the interaction between phase and group was .09 for pleasure and .14 for PA, showing that respectively $9 \%$ and $14 \%$ of the variance in the level change estimate for pleasure and PA can be explained by group differences. For NA, no significant differences between the groups were found, both the control group and the intervention groups significantly decreased in NA in the intervention phase. Effect sizes (i.e., Cohen's d) were 0.45 for pleasure, 0.49 for PA, and 0.25 for NA.

In the full model we added the time trends for the baseline and intervention phases to check whether the level change was due to a trend that already started in the baseline phase. As can be seen in Table 2, there were some significant trends in the baseline and intervention phases, but these trends did not differ between groups, indicating that the differences in level estimates between groups were not due to group differences in trends in the baseline phase.

Next, we analyzed differences between the lifestyle advice group and the tandem skydive group (see Table 3). Significant differences were found between the groups, but in an opposite direction than expected. The advice only group increased more in PA and decreased more in NA in the intervention phase than the skydive group. No significant differences were found in the full model. These findings indicate that the tandem skydive did not have an additional effect above the effects of the lifestyle advice. ${ }^{1}$

\footnotetext{
${ }^{1}$ For one participant in the tandem skydive group, the skydive was delayed for more than 2 weeks (i.e., 27 days). Although we extended the intervention period for this individual so that we had enough assessments after the skydive, this delay could have affected the results. Therefore, we checked whether exclusion of this participant affected our findings. No relevant differences were found for any of the analyses.
} 
Table 3

Differences in Estimates of Level and Slope Changes in PA, Pleasure, and NA, Between Both Intervention Groups

\begin{tabular}{|c|c|c|c|c|}
\hline & \multicolumn{2}{|c|}{ Only level estimate } & \multicolumn{2}{|l|}{ Complete model } \\
\hline & $\begin{array}{l}\text { Lifestyle advice } \\
(\mathrm{N}=22)\end{array}$ & $\begin{array}{l}\text { Lifestyle advice and skydive } \\
(\mathrm{N}=24)\end{array}$ & $\begin{array}{l}\text { Lifestyle advice } \\
(\mathrm{N}=22)\end{array}$ & $\begin{array}{l}\text { Lifestyle advice and skydive } \\
(\mathrm{N}=24)\end{array}$ \\
\hline Pleasure intercept & $53.81(1.49)$ & $54.18(1.89)$ & $53.95(1.66)$ & $52.72(1.81)$ \\
\hline Pleasure level estimate & $3.90(1.71)$ & $0.12(1.33)$ & $4.05(2.19)$ & $0.76(1.63)$ \\
\hline Pleasure slope baseline phase & & & $-0.01(0.03)$ & $0.03(0.02)$ \\
\hline Pleasure slope change & & & $0.01(0.03)$ & $-0.08(0.04)$ \\
\hline PA intercept & $52.84(1.92)$ & $53.93(1.62)$ & $49.79(1.62)$ & $50.70(1.82)$ \\
\hline PA level estimate & $6.35(1.17)^{*}$ & $2.61(1.32)^{*}$ & $2.42(1.30)$ & $1.46(1.38)$ \\
\hline PA slope baseline phase & & & $0.07(0.02)$ & $0.07(0.02)$ \\
\hline PA slope change & & & $-0.05(0.02)$ & $-0.11(.04)$ \\
\hline NA intercept & $25.73(1.96)$ & $22.85(1.67)$ & $29.19(2.18)$ & $27.56(2.09)$ \\
\hline NA level estimate & $-5.90(1.11)^{*}$ & $-2.90(0.93)^{\star}$ & $-1.35(0.93)$ & $0.19(0.76)$ \\
\hline NA slope baseline phase & & & $-0.08(0.03)$ & $-0.10(0.02)$ \\
\hline NA slope change & & & $0.06(0.03)$ & $0.14(0.04)$ \\
\hline
\end{tabular}

Note. $\mathrm{PA}=$ Positive Affect, $\mathrm{NA}=$ Negative Affect.

${ }^{\star} p<.05,{ }^{* *} p<.01,{ }^{* * *} p<.001$. Please note that the reported significance levels indicate whether the difference between groups (i.e., the interaction) was significant. To calculate the slope in the intervention phase, the coefficients for the slope in the baseline phase and the slope change should be summed.

\section{INDIVIDUAL LEVEL ANALYSES MOMENTARY DATA}

Significant residual random effect variance in the level change estimates was present and, hence, individual models were examined. As can be seen in the forest plots (Figures 3, 4, and 5), the majority of participants showed higher mean levels of pleasure and PA and lower mean levels of NA in the intervention phase, compared to the baseline phase, although substantial heterogeneity in the effect sizes were observed and also negative effects were observed, especially in the tandem skydive group. Further, very few differences in level estimates were apparent between the lifestyle advice group and the tandem skydive group.

Next, we examined whether sex, severity of anhedonia, duration of anhedonia, and advice adherence were associated with the extent to which individuals improved. Sex was significantly associated with the level change estimates in PA $(\beta=-.32, p<.05)$, in that females showed a lower increase in the level of PA during the intervention phase than males. No associations were found between sex and the level change estimates for pleasure $(\beta=-.25, p=.10)$ or NA $(\beta=.14, p=.35)$. Severity of anhedonia at baseline $(\beta=.03, p=.84$ for PA; $\beta=.07, p=.67$ for pleasure; $\beta=-.08, p=$ .60 for NA), duration of anhedonia at baseline $(\beta=$ $-.08, p=.59$ for PA; $\beta=-.17, p=.27$ for pleasure; $\beta=.05, p=.74$ for NA), and depressive symptoms at baseline $(\beta=-.10, p=.35$ for PA; $\beta=-.16, p=.10$ for pleasure; $\beta=-.06, p=.41$ for NA) were not associated with the level change estimates. Advice adherence was also not related to the level change estimates, $F(2)=.72, p=.49$ for PA; $F(2)=.01$, $p=.99$ for pleasure; $F(2)=.63, p=.54$ for NA.

\section{GROUP LEVEL ANALYSES MONTHLY DATA}

Levels of consummatory pleasure and depressive symptoms for each intervention group at pre- and post-intervention are depicted in Figure 6. A marginally significant group (control versus intervention) by time (pre- and post-intervention) interaction was found for consummatory pleasure, $F(2)=3.38, p=.07$, indicating that the intervention group increased more in pleasure than the control group. No significant interaction was found for depressive symptoms, $F(2)=0.48, p=.49$. Effect sizes (Cohen's $d$ ) were 0.48 for consummatory pleasure and 0.19 for depressive symptoms. Further, for the advice group versus the tandem skydive group, no significant interaction was found for pleasure, $F(2)=0.32, p=.57$ (see Figure 6A). For depressive symptoms, a marginally significant group by time interaction was found, $F(2)=3.85$, $p=.06$, in that the lifestyle advice group decreased more in depressive symptoms from pre- to postintervention than the skydive group (see Figure 6B).

\section{Discussion}

The main aim of this exploratory study was to examine whether personalized lifestyle advice and tandem skydiving could reduce anhedonia in young adults. Although the small sample size warrants prudence, we showed that the lifestyle advice can increase pleasure and PA in young adults with 
PERSONALIZED LifESTYLE ADVICE AND TANDEM SKYDIVES TO REDUCE ANHEDONIA 87

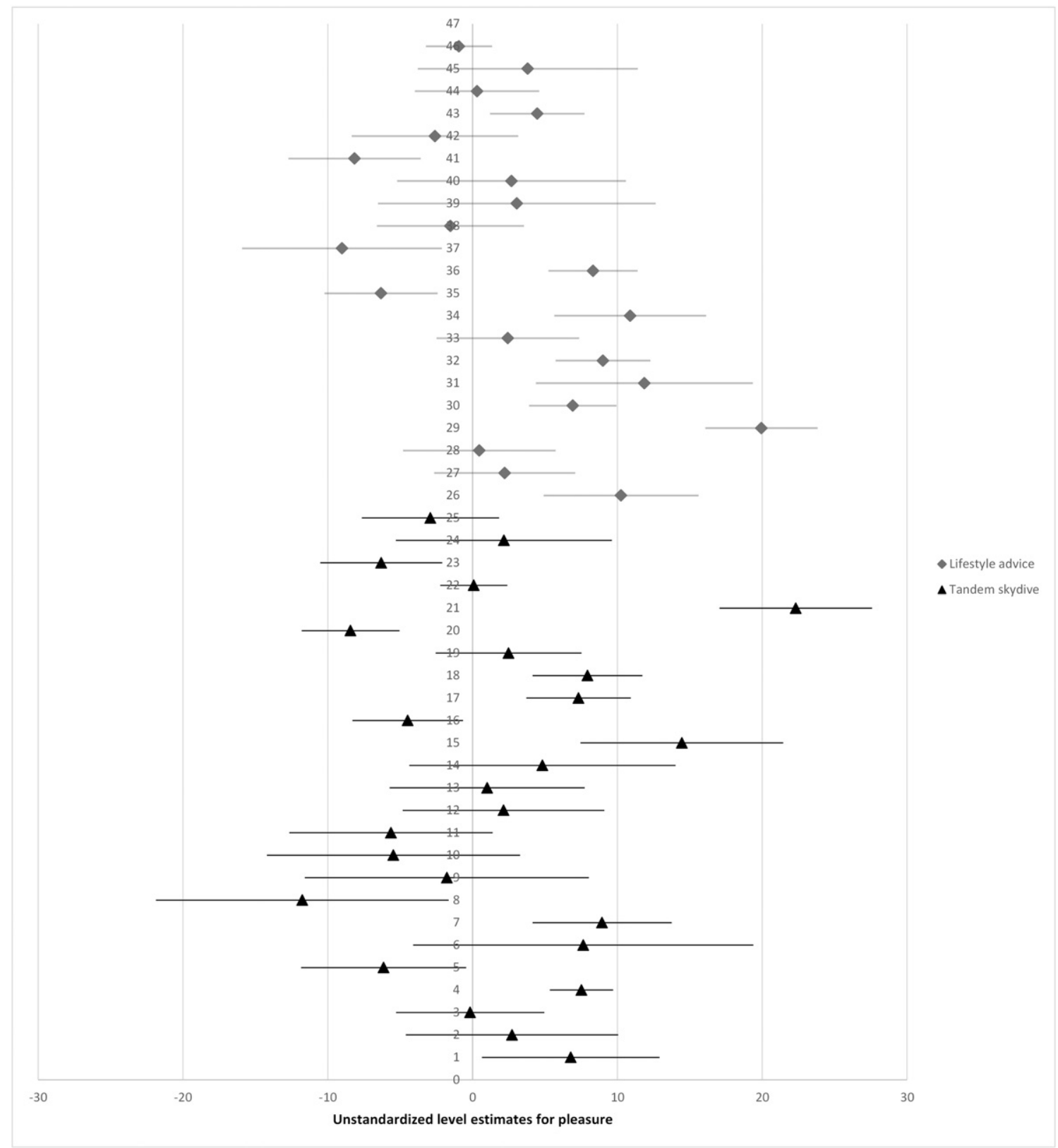

FIGURE 3 Forest plot of unstandardized level estimates for pleasure. Numbers on the $y$-axis represent the different individuals $(\mathrm{N}=46)$.

persistent anhedonia. Despite previous literature suggesting that a free-fall may reboot the reward system and could therewith provide additional benefits, we found no evidence of such an additional effect of the tandem skydive over and above the lifestyle advice.

Our findings indicate that providing anhedonic young adults with lifestyle advice can increase pleasure and PA. However, the effects were not found for all outcome variables and were small to moderate in size, which may be due to two reasons. First, the implementation of the lifestyle advice may take some time to really sink in and become part of an individual's repertoire of behaviors. The only other study providing personalized feedback on PA in depressed patients showed that the differences between groups became significant after 8 weeks (i.e., 2 weeks after the last feedback session; Kramer et al., 2014) and no significant differences between groups were present during the intervention period (Hartmann et al., 2015). In the present study, we were not able to examine these longer-term effects as our groups were no longer randomized after the intervention phase due to the free-choice intervention. This is a limitation, as we do not know how long the differences between groups in momentary 


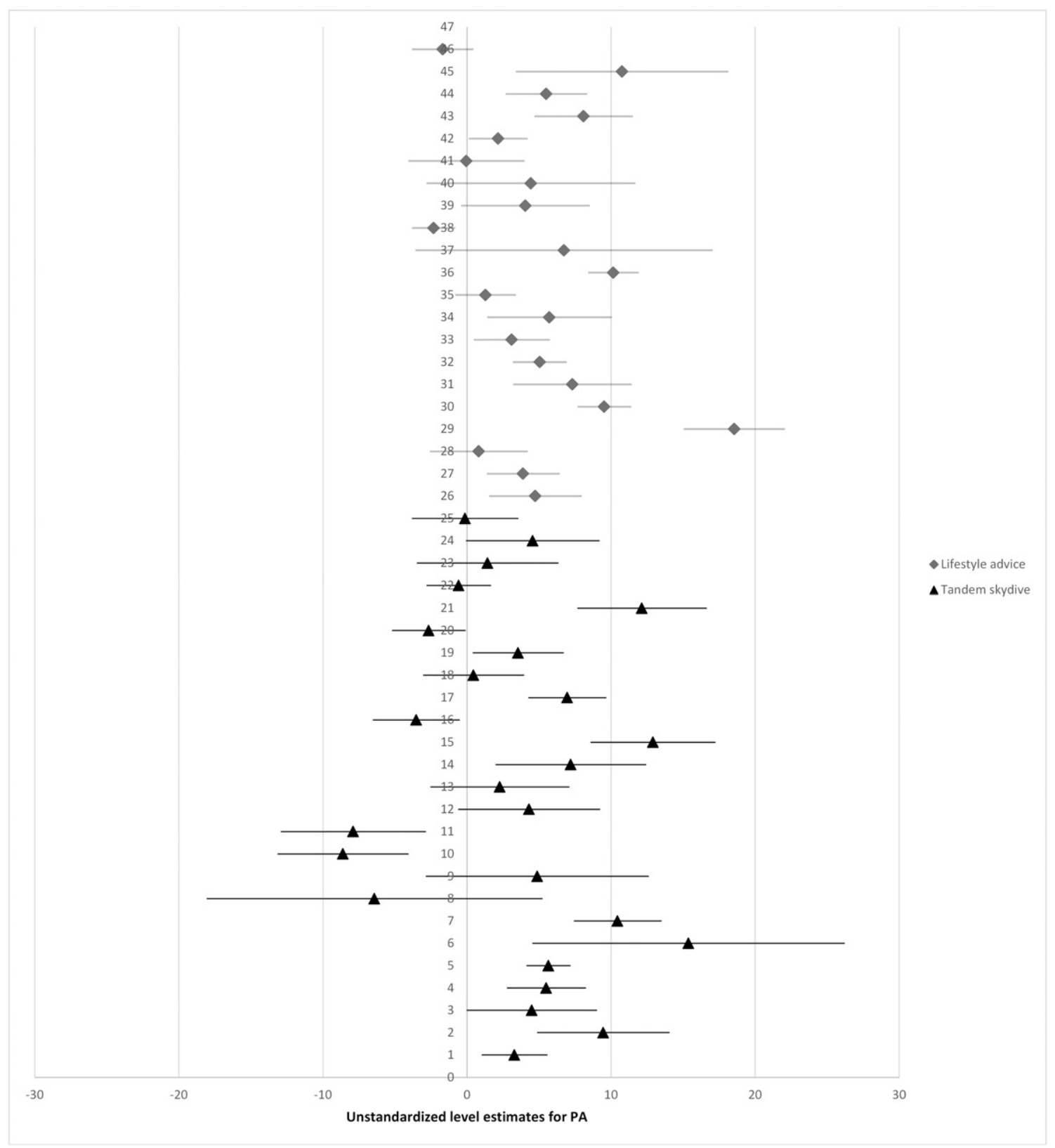

FIGURE 4 Forest plot of unstandardized level estimates for PA. Numbers on the $y$-axis represent the different individuals $(\mathrm{N}=46)$.

pleasure and PA lasted. Second, participants received their advice in the beginning of the intervention phase and did not receive any reminders or triggers. Using these extra reminders could have increased advice adherence. Third, the forest plots show that there is great heterogeneity in the intervention effects, which dilutes the average grouplevel effects. This heterogeneity may be explained by individual characteristics, but could also be due to differences in the type of advice provided (e.g., social activity versus physical activity). These findings highlight the need to further explore whether individual characteristics and the type of advice could explain the effectiveness of the lifestyle advice.

In the present study, we provided explicit advice on which behaviors participants could change and expected that this would be more effective than only showing participants in which situations they experienced PA, as was done by Kramer and colleagues (Hartmann et al., 2015; Kramer et al., 2014). The results from our study indicate that concrete advice may indeed be more effective, as we found immediate increases in momentary pleasure and PA, whereas no effects were found on PA in the study in which only feedback was provided 
PERSONALIZED LIFESTYLE ADVICE AND TANDEM SKYDIVES TO REDUCE ANHEDONIA 89

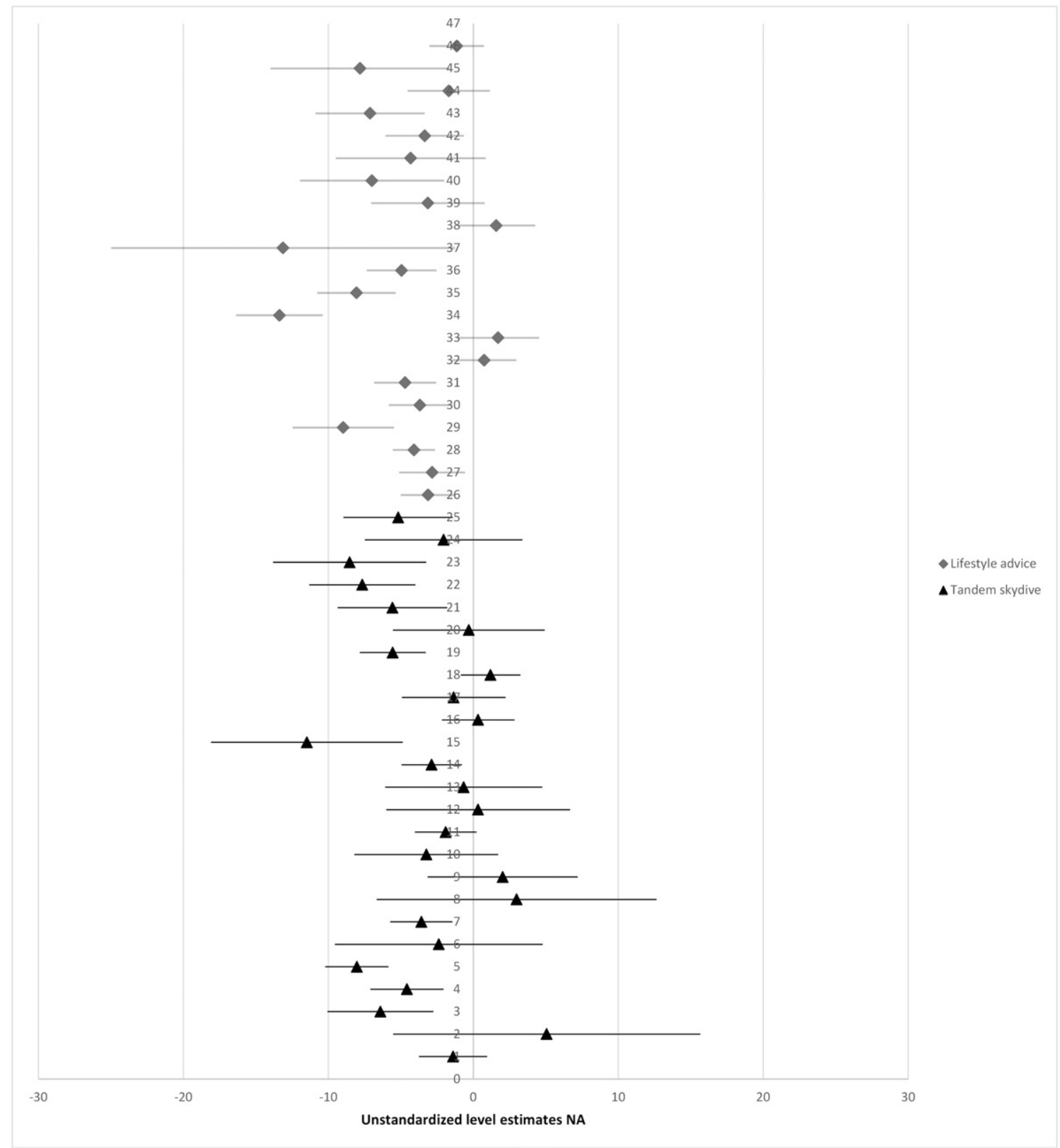

FIGURE 5 Forest plot of unstandardized level estimates for NA. Numbers on the $y$-axis represent the different individuals $(N=46)$.

\section{A: Consummatory pleasure}

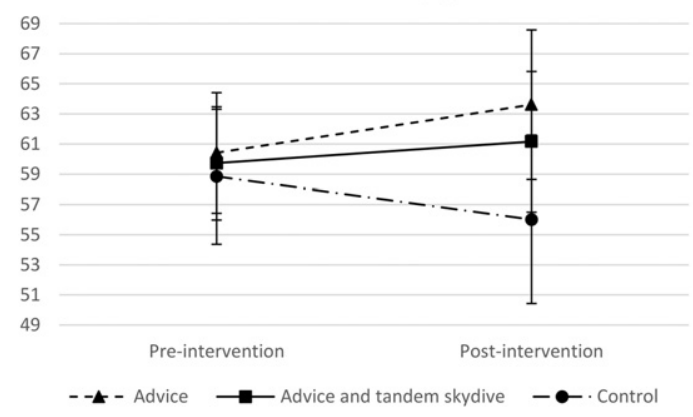

B: Depressive symptoms

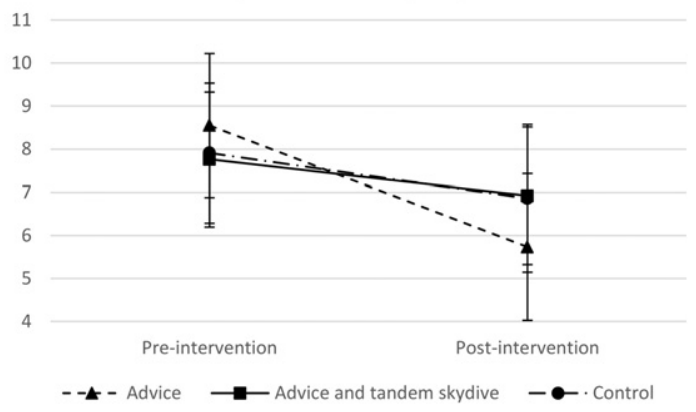

FIGURE 6 Comparison between the three intervention groups in monthly assessments of consummatory pleasure as measured by the DOPS (6A) and depressive symptoms as measured by the PHQ-9 (6B). 
(Hartmann et al., 2015). A further explanation for the stronger effects in our study is that our advice was, if possible, based on statistically significant associations with pleasure, whereas the Kramer et al. study only presented descriptive feedback. As our report was based on more robust findings, it may have had a greater impact.

In our analyses, we excluded the measures between the intervention allocation and the intervention session, because participants already knew which intervention they would receive during this period. For momentary levels of PA and NA, we showed that participants in the lifestyle advice only group slightly improved after being informed about the intervention allocation. This indicates that the knowledge that participants would receive help for their problems in the nearby future already improved their PA and NA levels. Interestingly, this was not the case for the tandem skydive group. A possible explanation is that the prospect of a tandem skydive evoked stress and anxiety in some individuals, which counterbalanced any positive effects.

Our findings are conclusive in showing that thrill experiences like a tandem skydive should not be suggested as a possible treatment for anhedonia, as the skydive did not provide the hypothesized motivational boost to kickstart the implementation of the lifestyle advice. Possibly, a tandem skydive is only effective in increasing immediate pleasure and motivation, as was found in previous studies (Meyer et al., 2015; Wang \& Tsien, 2011), and does not have a persistent effect. Our lack of effects may indicate that a skydive is not effective in decreasing anhedonia. Although we hypothesized that participating in a single skydive could provide a motivational boost to individuals, the effects may have been short-lasting and we cannot exclude the possibility that multiple skydiving experiences are needed to achieve long-lasting effects.

However, previous cross-sectional research has revealed an association between regular skydiving experience and high levels of anhedonia (Franken et al., 2006), which could indicate that repeated exposure to skydiving leads to increased levels of anhedonia and hence should be avoided. It may also be that individuals who experience anhedonia tend to seek out repeated high-risk activities in order to obtain the "natural high" associated with these activities. The cross-sectional nature of this study prevents statements about the direction of the effects. Further longitudinal research is needed to explore the direction of effects between skydiving and anhedonia.

It may also be possible that a skydive is effective only for some individuals, as the individual-level analyses suggest. Anecdotal evidence from participants suggests that the skydive may have increased self-esteem and reduced anxiety in some individuals. For example, one of the participants reported that "Whenever I had to do something frightening, I was able to put this into perspective. Because I have done something so extremely scary, everything else seems less frightening." Hence, although a skydive may not be effective in rebooting the reward system and increasing pleasure in general, it might be beneficial for individuals with low selfesteem by boosting their self-confidence. The effectiveness may also depend on how individuals appraised the skydive afterwards, as it did seem to have an effect on the participant described above, who overcame her own fears. Further research should include questionnaires measuring the appraisal of the event and could even use qualitative interview data to explore how the skydive may affect individuals.

The findings from the present study may have clinical implications. Although our effect sizes were small to moderate, it is difficult to interpret these effects in terms of clinical relevance, given that there are no clinical cutoffs with regard to momentary levels of pleasure and PA. Hence, more research is needed in clinical samples in order to explore the clinical relevance of these findings. Pending further research in clinical samples, our intervention could be easily implemented in general health care. For example, providing patients who are on a waiting list to receive treatment with feedback on daily life patterns of mood and behavior during the waiting time could already decrease their symptoms and set the stage for further improvement during the "actual" treatment. As recent research shows that automated feedback based on momentary assessments is already possible (Emerencia et al., 2015; van der Krieke et al., 2015), such an intervention will not require a lot of time and effort from clinicians. The information derived from the momentary assessments and personalized feedback could provide a valuable starting point for treatment, as it enables tailor-made treatment for each individual. Hence, the most important advantages of personalized feedback are that it is cost-effective, easily accessible, and can be used in addition to existing treatments. It may also be beneficial for patients who do not respond to standard treatments, as the personalized feedback may reveal new potential targets for behavioral change. In addition, automated feedback based on momentary assessments can be used for different kinds of mental health problems, as the variables of interest for the feedback can be adapted. It is important to note that this automated feedback should include a directive component, that is, concrete suggestions on which factors individuals can change, as we showed that this is more effective than only offering feedback 
without concrete suggestions (Kramer et al., 2014). Our intervention may not be applicable to all individuals with anhedonia. For example, excessive focusing on increasing PA and pleasure might induce mania in individuals at risk for bipolar disorder. Further research is needed in various clinical populations to carefully examine the effects of personalized lifestyle advice.

Finally, we showed that the extent to which individuals improved was highly variable. Surprisingly, variation in improvement was not related to the severity and duration of anhedonia, nor to advice adherence. Although we expected that the extent to which participants followed up on our advice would lead to stronger increases in PA and pleasure, possibly, our broad measure of advice adherence could explain the large variations found. That is, some participants may not have been very adherent in general, but still have followed up on the most effective advice. Further, we only relied on participants' own report of their advice adherence; which may have been socially desirable. Further examination of the actual change in behavior is needed to elucidate these effects (Snippe et al., 2015).

\section{STRENGTHS AND LIMITATIONS}

The present study had several strengths. It is, to our knowledge, the very first to use momentary data to provide personalized lifestyle advice and evaluate their effects. Because of our unique design consisting of a baseline phase and an intervention phase and the high number of momentary assessments in each phase (i.e., more than 90 per phase), we were able to examine within-person effects at the grouplevel and at the individual level. Compliance was excellent, as the average number of completed assessments was $92.4 \%$. Potential explanations for these high compliance rates in comparison to other momentary assessment studies with a long duration (Trull et al., 2008) could be that (a) participants knew that they would receive feedback based on their momentary assessments, which may have enhanced motivation, and (b) participants were instructed that they would only receive the monetary compensation if they filled out at least $80 \%$ of the momentary assessments. Our high compliance rate shows that it is feasible to conduct a long-term diary study among anhedonic young adults.

Despite these strengths, several limitations need to be acknowledged. First, although we increased our power by including on average 190 momentary assessments per individual, the number of participants per intervention group was relatively low. This might explain why several of the differences tested did not reach statistical significance, particularly for the monthly collected data. Second, we only selected participants who were willing to conduct a tandem skydive, which may have led to a biased sample. However, this bias, if any, is probably limited, because only $25(9.3 \%)$ of the eligible individuals were excluded because they were not willing to participate in a tandem skydive. Further, we showed that this group did not differ from the group that was willing to perform a skydive in severity of anhedonia, the level of consummatory anhedonia, and depressive symptoms. Third, the majority of our sample was female. Please note that this was due to a high number of females in the survey study, and not due to higher prevalence of anhedonia in females. The small number of males implied that we had little power to test sex differences at the group level. Our findings at the individual level suggest that males benefit more from lifestyle advice than females, but further research in larger samples is needed to replicate these findings. Fourth, one-third of our sample only experienced minimal to mild depressive symptoms; therefore, the generalizability of our findings to individuals with depressive symptoms is limited. However, we showed that the level of depressive symptoms did not affect improvement, which indicates that the lifestyle advice was effective for individuals with different levels of depressive symptoms. Fifth, we cannot exclude the possibility that differences between the control group and the intervention groups are due to the placebo effect of receiving an active intervention. Future research should include a more active control group to examine this alternative explanation. Finally, as mentioned earlier, we were not able to examine long-term effects of the interventions, because we included the free-choice intervention immediately after the intervention period. Further research is needed to explore whether lifestyle advice has a long-term effect on pleasure and PA in anhedonic young adults.

\section{CONCLUSIONS}

This study indicates that providing anhedonic young adults with personalized lifestyle advice may increase pleasure and PA. In addition, we showed that it is feasible to collect diary data in anhedonic young adults for a fairly long time without much loss of information. These findings are relevant for clinical practice, as they suggest that it is both promising and feasible to develop momentary interventions that can be implemented as additions to treatment as usual or while patients are on waiting lists for treatment.

\section{Conflict of Interest Statement}

The authors declare that there are no conflicts of interest. 


\section{Appendix A. Description of Measurement of Model Variables}

\begin{tabular}{|c|c|c|}
\hline Variables & Item & Answer categories \\
\hline Pleasure & I have experienced pleasure since the last assessment & VAS 0-100 (not at all - very much) \\
\hline Social context & Since the last assessment, I was (multiple answers possible): & $\begin{array}{l}\text { alone; with partner; with family; with friends; with } \\
\text { classmates; with acquaintances; with strangers. }\end{array}$ \\
\hline Activities & $\begin{array}{l}\text { I have participated in the following activities since the last } \\
\text { assessment (multiple answers possible): }\end{array}$ & $\begin{array}{l}\text { watching TV; listening to music; studying; reading } \\
\text { a book or magazine; shopping; using the internet; } \\
\text { gaming; work; having sex; household chores; } \\
\text { sports; going to a bar or club; going out for dinner; } \\
\text { going to the movies, theatre, museum or concert; } \\
\text { sleeping; using social media; hobbies; other, } \\
\text { namely.... }\end{array}$ \\
\hline Substance use & $\begin{array}{l}\text { I have used the following substances since the last } \\
\text { assessment: }\end{array}$ & $\begin{array}{l}\text { nothing; caffeine; nicotine; medication; alcohol; } \\
\text { cannabis; stimulants; sedatives; other drugs }\end{array}$ \\
\hline Stress & How busy have I been since the last assessment & $\begin{array}{l}\text { too busy; pleasantly busy; neutral; pleasantly } \\
\text { quiet; too quiet }\end{array}$ \\
\hline Time alone & [When alone has been checked:] Time spend alone: & VAS scale (very little - very much) \\
\hline Social interaction & How much have I been talking to other people? & VAS 0-100 (not at all - very much) \\
\hline Physical activity & I have been physically active since the last assessment & VAS 0-100 (not at all - very much) \\
\hline Time outside & I have been outside since the last assessment & VAS 0-100 (not at all - very much) \\
\hline Worrying & I have been worrying & VAS 0-100 (not at all - very much) \\
\hline $\begin{array}{l}\text { Sweet and savory } \\
\text { snacks }\end{array}$ & $\begin{array}{l}\text { How many sweet snacks (e.g., cookies, sweets) did I eat? } \\
\text { How many savory snacks (e.g., French fries, potato chips) } \\
\text { did I eat? }\end{array}$ & VAS 0-100 (nothing - a lot) \\
\hline $\begin{array}{l}\text { Physical } \\
\text { discomfort }\end{array}$ & $\begin{array}{l}\text { I have experienced physical discomfort since the last } \\
\text { assessments (head ache, diarrhea, heavy legs, etc.) }\end{array}$ & VAS 0-100 (not at all - very much) \\
\hline
\end{tabular}

\section{Appendix B. Details of the Lifestyle Report}

The descriptive information of the lifestyle report included pie charts representing the number of assessments spent in different social contexts and the number of activities (see Fig. B1 for an example); a line graph delineating the level of pleasure during the 90 assessments (e.g., Fig. B2); two charts showing the level of pleasure experienced in different social contexts and during different activities (e.g., Fig. B3); and scatter plots depicting the association between continuous lifestyle factors that were not included in the personal networks and pleasure. For the comparison with norm groups, a bar chart was presented with two bars for each of the variables reported in Table A1 (e.g., Fig. B4). The norm data were based on the data from the screening survey among 2,937 young adults, which were used to create mean norm scores for males and females separately.

The personal networks were based on two different approaches, because combining categorical and continuous predictors in a single time-series analysis is problematic and not all time-series models can handle large numbers of predictors. For the association between categorical predictors and pleasure (see Table A1), we used Auto Regressive Moving
Average (ARMA) models (Brandt \& Williams, 2007). By fitting ARMA models to the residuals, we adjusted for autocorrelation in the time series. In all models, we first tested whether we needed to correct for time trends (i.e., linear and quadratic), day of the week, special events (positive or negative), or menstruation for females. The Ljung-Box test was used to explore whether the residuals represented "white noise." If this was not the case, we checked whether residual autocorrelation was present by using (partial) autocorrelation functions (ACFs and PACFs) and added ARMA parameters to the regression model until the Ljung-Box test became nonsignificant. Series that showed heteroscedasticity were stabilized by using the natural log of the scores. The final model selection was based on the Bayesian Information Criterion (BIC) and the Ljung-Box test. When the final model was determined, all categorical predictors were tested in separate models, and significant associations were presented in text in the lifestyle report. Models were implemented using the SPSS22 Forecasting module. The significance level was set to 0.05 .

To examine potential reciprocal and time-lagged associations between pleasure and the continuous variables (see Table A1), we used Vector Autoregressive modeling (VAR) (Brandt \& Williams, 2007). This 
procedure was automated by using Autovar, an open source $\mathrm{R}$ package that automatically fits and evaluates VAR models (Emerencia et al., 2015). We allowed for a maximum of six variables in each network. Variables were selected based on sufficient variability (i.e., Mean Squared Successive Difference $>50$; MSSD), and reasonably low skewness (i.e., zskewness $<4$ ). If more than six variables met the criteria, the best distributed variables were chosen (i.e., the least skewed variables of variables with the highest MSSD). If less than six variables met the criteria, only those variables were included in the model. Pleasure was always included, providing that variability and skewness met the criteria mentioned above. We estimated VAR models with one time lag. This yields estimates of the cross-lagged as well as the simultaneous associations between variables. Trend variables (i.e., linear and quadratic time trend) were included in case of non-stationarity. Dummy variables for time of day (i.e., afternoon, evening) were always included. Models with dummy variables for day of the week and with log-transformed variables were tested. From the models that met the assumptions of stability, homoscedasticity and normality, Autovar chose the best fitting model based on the BIC (i.e., Bayesian Information Criterion). Network plots for simultaneous (i.e., contemporaneous associations) and dynamic (i.e., lag 1 associations) models were created using Data-Driven Documents-3 JavaScript library (http://d3js.org) (see Figs. B5 and B6 for examples of simultaneous and dynamic network plots). All analyses were checked by another team member to avoid mistakes.

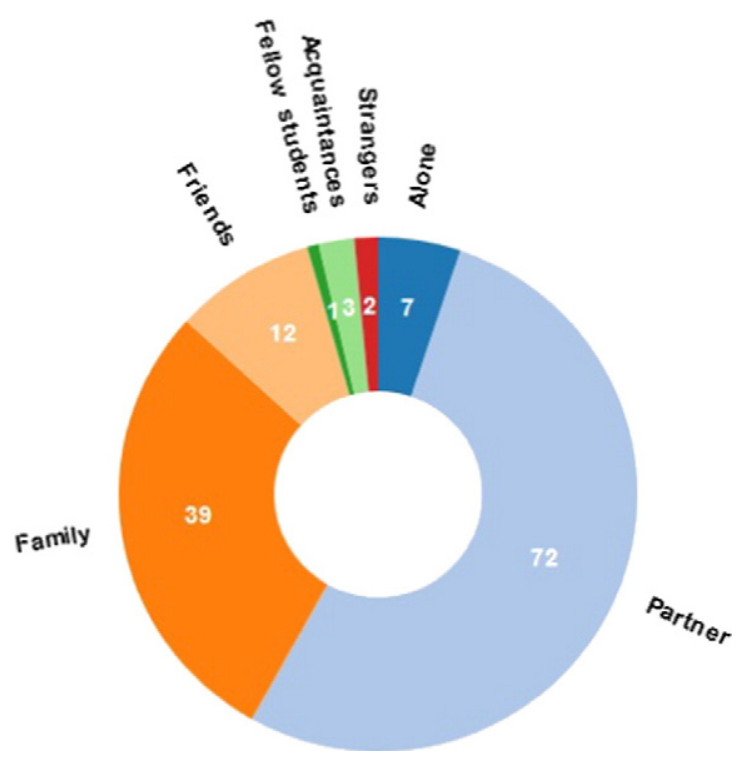

FIGURE BI Pie chart for number of assessments in different types of company.

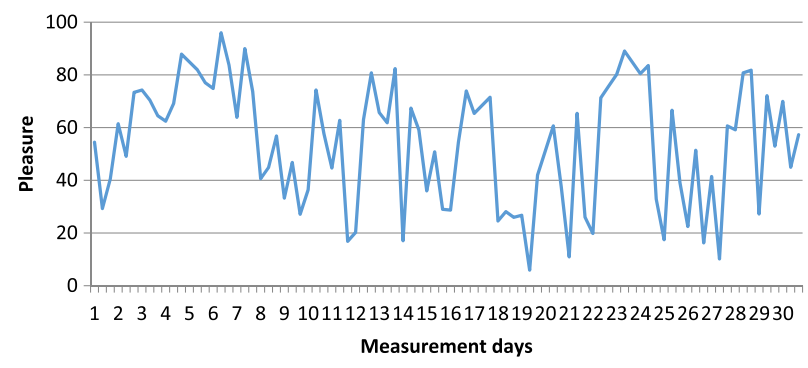

FIGURE B2 Line graph depicting level of pleasure during baseline phase.

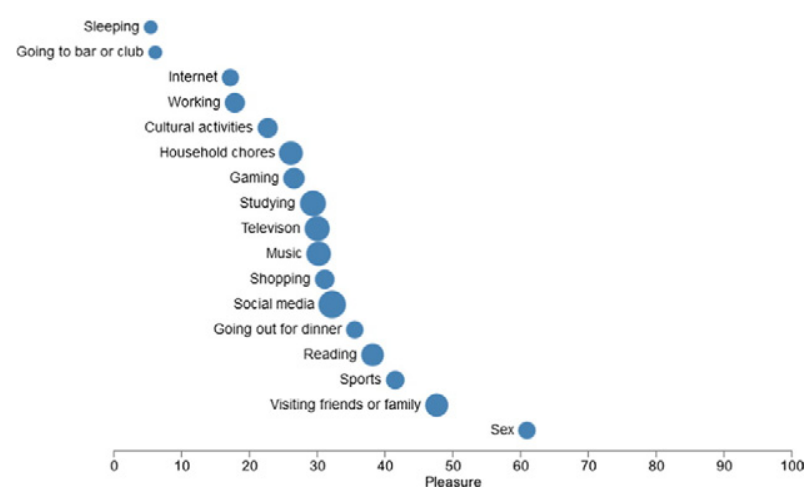

FIGURE B3 Activities ranked by level of pleasure.

Note. Larger circles indicate higher frequency of the activity, smaller circles lower frequency.

You in comparison to female peers

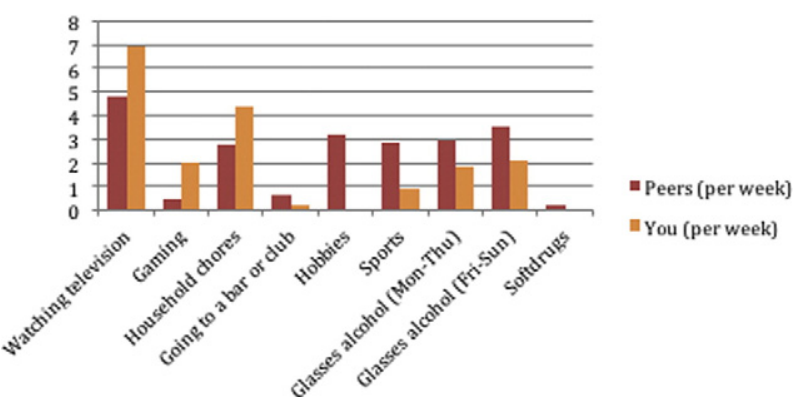

FIGURE B4 Frequency of participants' activities compared to norm group.

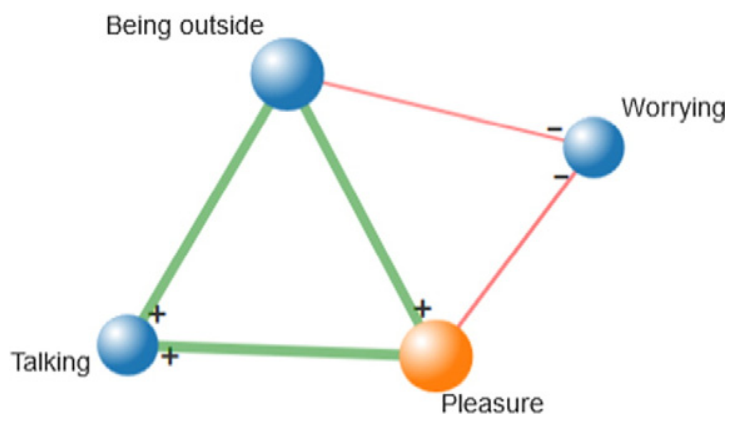

FIGURE B5 Personal network for simultaneous associations. 


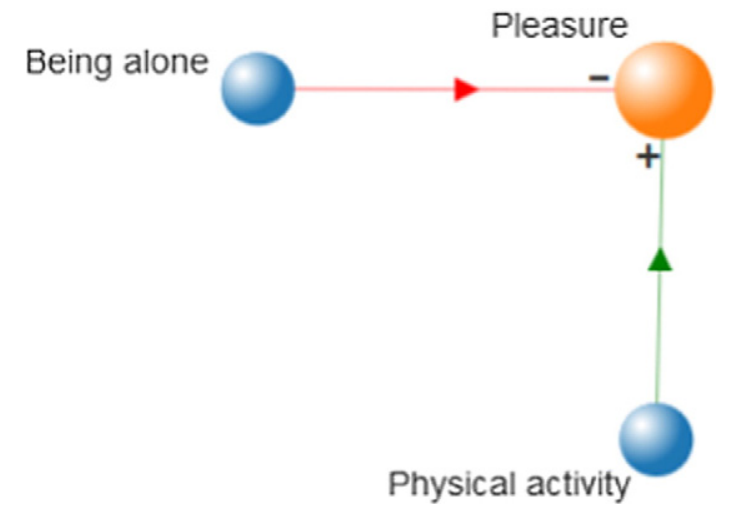

FIGURE B6 Personal network for dynamic associations (i.e., lag I).

\section{Appendix C. Additional Descriptive Statistics for the Three Intervention Groups}

Using the Adult Self-Report questionnaire (ASR; Achenbach \& Rescorla, 2001) that was assessed in the screening survey, we calculated cut-off scores for the DSM-based problem scales Depressive problems, Anxiety problems, Avoidant Personality problems, ADHD problems, antisocial personality problems, and total problems. Based on these cut-offs, participant scores were classified as non-clinical, sub-clinical or clinical. Results can be found in Table C1, for each intervention group separately.

Table C1

Descriptive Statistics for the Three Intervention Groups.

\begin{tabular}{|c|c|c|c|}
\hline & $\begin{array}{l}\text { No } \\
\text { intervention } \\
(\mathrm{N}=22)\end{array}$ & $\begin{array}{l}\text { Lifestyle } \\
\text { advice } \\
(\mathrm{N}=22)\end{array}$ & $\begin{array}{l}\text { Lifestyle advice } \\
\text { and tandem } \\
\text { skydive } \\
(\mathrm{N}=25)\end{array}$ \\
\hline \multicolumn{4}{|c|}{ Depressive problems } \\
\hline Non-clinical & $11(50 \%)$ & $10(45.5 \%)$ & $12(48 \%)$ \\
\hline Sub-clinical & $6(27.3 \%)$ & $6(27.3 \%)$ & $8(32.0 \%)$ \\
\hline Clinical & $5(22.7 \%)$ & $6(27.3 \%)$ & $5(20.0 \%)$ \\
\hline \multicolumn{4}{|c|}{ Anxiety problems } \\
\hline Non-clinical & $18(81.8 \%)$ & $17(77.3 \%)$ & $21(84.0 \%)$ \\
\hline Sub-clinical & $1(4.5 \%)$ & $3(13.6 \%)$ & $4(16.0 \%$ \\
\hline Clinical & $3(13.6 \%)$ & $2(9.1 \%)$ & $0(0 \%)$ \\
\hline \multicolumn{4}{|c|}{ Avoidant personality problems } \\
\hline Non-clinical & $17(77.3 \%)$ & $14(63.6 \%)$ & $20(80.0 \%)$ \\
\hline Sub-clinical & $2(9.1 \%)$ & $2(9.1 \%)$ & $1(4.0 \%)$ \\
\hline Clinical & $3(13.6 \%)$ & $6(27.3 \%)$ & $4(16.0 \%)$ \\
\hline \multicolumn{4}{|l|}{ ADHD problems } \\
\hline Non-clinical & $17(77.3 \%)$ & $18(81.8 \%)$ & $19(76.0 \%)$ \\
\hline Sub-clinical & $2(9.1 \%)$ & $2(9.1 \%)$ & $3(12.0 \%)$ \\
\hline Clinical & $3(13.6 \%)$ & $2(9.1 \%)$ & $3(12.0 \%)$ \\
\hline \multicolumn{4}{|c|}{ Antisocial personality problems } \\
\hline Non-clinical & $19(86.4 \%)$ & $21(95.5 \%)$ & $23(92.0 \%)$ \\
\hline Sub-clinical & $3(13.6 \%)$ & $1(4.5 \%)$ & $1(4.0 \%)$ \\
\hline Clinical & $0(0 \%)$ & $0(0 \%)$ & $1(4.0 \%)$ \\
\hline
\end{tabular}

Table C1 (continued)

\begin{tabular}{lccc}
\hline & $\begin{array}{l}\text { No } \\
\text { intervention } \\
(\mathrm{N}=22)\end{array}$ & $\begin{array}{l}\text { Lifestyle } \\
\text { advice } \\
(\mathrm{N}=22)\end{array}$ & $\begin{array}{l}\text { Lifestyle advice } \\
\text { and tandem } \\
\text { skydive } \\
(\mathrm{N}=25)\end{array}$ \\
\hline $\begin{array}{l}\text { Total problems } \\
\text { Non-clinical }\end{array}$ & $13(59.1 \%)$ & $10(45.5 \%)$ & $12(49 \%)$ \\
Sub-clinical & $4(18.2 \%)$ & $7(31.8 \%)$ & $11(44.0 \%)$ \\
Clinical & $5(22.7 \%)$ & $5(22.7 \%)$ & $2(8 \%)$ \\
Depressive symptoms (PHQ-9) & & \\
Minimal & $3(13.6 \%)$ & $4(19.0 \%)$ & $4(16.0 \%)$ \\
Mild & $11(50 \%)$ & $6(28.6 \%)$ & $10(40 \%)$ \\
Moderate & $5(22.7 \%)$ & $8(38.1 \%)$ & $7(28.0 \%)$ \\
Moderately & $3(13.6 \%)$ & $3(14.3 \%)$ & $4(16.0 \%)$ \\
severe & & & \\
Severe & $0(0 \%)$ & $1(4.5 \%)$ & $0(0 \%)$ \\
\hline
\end{tabular}

\section{References}

Achenbach, T. M., \& Rescorla, L. A. (2001). Manual for the ASEBA school-age forms and profiles: An integrated system of multi-informant assessment. Burlington, VT: Research Center for Children, Youth, and Families.

Aguinis, H., Gottfredson, R. K., \& Culpepper, S. A. (2013). Best-Practice Recommendations for Estimating Cross-Level Interaction Effects Using Multilevel Modeling. Journal of Management, 39(6), 1490-1528. http://dx.doi.org/10.1177/ 0149206313478188

American Psychiatric Association. (2008). The Practice of Electroconvulsive Therapy: Recommendations for Treatment, Training, and Privileging (A Task Force Report of the American Psychiatric Association). American Psychiatric Pub.

American Psychiatric Association. (2013). Diagnostic and statistical manual of mental disorders (5th ed.). Arlington, VA: American Psychiatric Publishing.

Anderson, I. M., \& Fergusson, G. M. (2013). Mechanism of action of ECT. In The ECT Handbook (pp. 1-7). RCPsych Publications.

Bennik, E. C., Nederhof, E., Ormel, J., \& Oldehinkel, A. J. (2014). Anhedonia and depressed mood in adolescence: course, stability, and reciprocal relation in the TRAILS study. European Child \& Adolescent Psychiatry, 23(7), 579-586. http://dx.doi.org/10.1007/s00787-013-0481-z

Brandt, P. T., \& Williams, J. T. (2007). Multiple Time Series Models. SAGE.

Chatterton, R. T., Vogelsong, K. M., Lu, Y., \& Hudgens, G. A. (1997). Hormonal Responses to Psychological Stress in Men Preparing for Skydiving. The Journal of Clinical Endocrinology \& Metabolism, 82 (8), 2503-2509. http://dx.doi.org/10.1210/jcem.82.8.4133

Cohen, J. (1988). Statistical Power Analysis for the Behavioral Sciences (2nd ed.). Hillsdale, NJ: Routledge.

Cuijpers, P., van Straten, A., \& Warmerdam, L. (2007). Behavioral activation treatments of depression: A metaanalysis. Clinical Psychology Review, 27(3), 318-326. http://dx.doi.org/10.1016/j.cpr.2006.11.001

Emerencia, A., van der Krieke, L., Bos, E., de Jonge, P., Petkov, N., \& Aiello, M. (2015). Automating vector autoregression on electronic patient diary data. IEEE Journal of Biomedical and Health Informatics, PP(99), 1-1. http://dx.doi.org/10. 1109/JBHI.2015.2402280 
Favrod, J., Giuliani, F., Ernst, F., \& Bonsack, C. (2010). Anticipatory Pleasure Skills Training: A New Intervention to Reduce Anhedonia in Schizophrenia. Perspectives in Psychiatric Care, 46(3), 171-181. http://dx.doi.org/10. 1111/j.1744-6163.2010.00255.x

Favrod, J., Nguyen, A., Fankhauser, C., Ismailaj, A., Hasler, J. -D., Ringuet, A., ... Bonsack, C. (2015). Positive Emotions Program for Schizophrenia (PEPS): A pilot intervention to reduce anhedonia and apathy. BMC Psychiatry, 15, 231. http://dx.doi.org/10.1186/s12888-015-0610-y

Franken, I. H. A., Zijlstra, C., \& Muris, P. (2006). Are nonpharmacological induced rewards related to anhedonia? A study among skydivers. Progress in Neuro-Psychopharmacology and Biological Psychiatry, 30(2), 297-300. http:// dx.doi.org/10.1016/j.pnpbp.2005.10.011

Fusar-Poli, P., Papanastasiou, E., Stahl, D., Rocchetti, M., Carpenter, W., Shergill, S., \& McGuire, P. (2015). Treatments of Negative Symptoms in Schizophrenia: Meta-Analysis of 168 Randomized Placebo-Controlled Trials. Schizophrenia Bulletin, 41(4), 892-899. http://dx.doi.org/10.1093/schbul/ sbu170

Gabbay, V., Johnson, A. R., Alonso, C. M., Evans, L. K., Babb, J. S., \& Klein, R. G. (2015). Anhedonia, but not Irritability, Is Associated with Illness Severity Outcomes in Adolescent Major Depression. Journal of Child and Adolescent Psychopharmacology, 25(3), 194-200. http://doi.org/10. 1089/cap.2014.0105

Grillo, L. (2016). A Possible Role of Anhedonia as Common Substrate for Depression and Anxiety. Depression Research and Treatment, 2016, e1598130. http://dx.doi.org/10.1155/ 2016/1598130

Gutkovich, Z., Morrissey, R. F., Espaillat, R. K., Dicker, R., Gutkovich, Z., Morrissey, R. F., . . . Dicker, R. (2010). Anhedonia and Pessimism in Hospitalized Depressed Adolescents. Depression Research and Treatment, e795173. http://dx.doi.org/10.1155/2011/795173

Hankin, B. L., \& Abramson, L. Y. (2001). Development of gender differences in depression: An elaborated cognitive vulnerability-transactional stress theory. Psychological Bulletin, 127, 773-796. http://doi.org/10.1037//00332909.127.6.773

Hare, O. A., Wetherell, M. A., \& Smith, M. A. (2013). State anxiety and cortisol reactivity to skydiving in novice versus experienced skydivers. Physiology \& Behavior, 118, 40-44. http://doi.org/10.1016/j.physbeh.2013.05.011

Hartmann, D. P., Gottman, J. M., Jones, R. R., Gardner, W., Kazdin, A. E., \& Vaught, R. S. (1980). Interrupted time-series analysis and its application to behavioral data. Journal of Applied Behavior Analysis, 13(4), 543-559. http://dx.doi.org/ 10.1901/jaba.1980.13-543

Hartmann, J. A., Wichers, M., Menne-Lothmann, C., Kramer, I., Viechtbauer, W., Peeters, F., . . . Simons, C. J. P. (2015). Experience Sampling-based personalized feedback and positive affect: A randomized controlled trial in depressed patients. PLOS ONE, 10(6), e0128095. http://doi.org/10. 1371/journal.pone.0128095

Hox, J. J. (2002). Multilevel Analysis: Techniques and Applications. New York: Lawrence Erlbaum Associates.

Huitema, B. E., \& Mckean, J. W. (2000). Design Specification Issues in Time-Series Intervention Models. Educational and Psychological Measurement, 60(1), 38-58. http://dx.doi. org/10.1177/00131640021970358

Kanter, J. W., Manos, R. C., Bowe, W. M., Baruch, D. E., Busch, A. M., \& Rusch, L. C. (2010). What is behavioral activation? A review of the empirical literature. Clinical Psychology Review, 30(6), 608-620. http://doi.org/10. 1016/j.cpr.2010.04.001
Kramer, I., Simons, C. J. P., Hartmann, J. A., MenneLothmann, C., Viechtbauer, W., Peeters, F., . . . Wichers, M. (2014). A therapeutic application of the experience sampling method in the treatment of depression: a randomized controlled trial. World Psychiatry, 13(1), 68-77. http://doi.org/10.1002/wps.20090

Kroenke, K., Spitzer, R. L., \& Williams, B. W. (2001). The PHQ-9. Journal of General Internal Medicine, 16(9), 606-613.

Kupferberg, A., Bicks, L., \& Hasler, G. (2016). Social functioning in major depressive disorder. Neuroscience \& Biobehavioral Reviews, 69, 313-332. http://doi.org/10. 1016/j.neubiorev.2016.07.002

Lepage, M., Sergerie, K., Pelletier, M., \& Harvey, P. -O. (2007). Episodic Memory Bias and the Symptoms of Schizophrenia. The Canadian Journal of Psychiatry, 52(11), 702-709. http://dx.doi.org/10.1177/070674370705201104

Masselink, M., van Roekel, E., Heininga, V. E., Vrijen, C., Nederhof, E., \& Oldehinkel, A. J. (2016). Domains of Pleasure Scale (DOPS): A novel questionnaire to measure anhedonia. Manuscript submitted for publication.

Meyer, V. J., Lee, Y., Böttger, C., Leonbacher, U., Allison, A. L., \& Shirtcliff, E. A. (2015). Experience, cortisol reactivity, and the coordination of emotional responses to skydiving. Frontiers in Human Neuroscience, 9. http://dx.doi.org/10. 3389/fnhum.2015.00138

Morris, S. B. (2008). Estimating Effect Sizes From PretestPosttest-Control Group Designs. Organizational Research Methods, 11(2), 364-386. http://dx.doi.org/10.1177/ 1094428106291059

Muthén, L. K., \& Muthén, B. O. (1998). Mplus user's guide (5th ed.). Los Angeles, CA: Muthén \& Muthén.

Myin-Germeys, I., Klippel, A., Steinhart, H., \& Reininghaus, U. (2016). Ecological momentary interventions in psychiatry. Current Opinion in Psychiatry, 29(4), 258-263. http://dx.doi.org/10.1097/YCO.0000000000000255

Myin-Germeys, I., Oorschot, M., Collip, D., Lataster, J., Delespaul, P., \& Van Os, J. (2009). Experience sampling research in psychopathology: Opening the black box of daily life. Psychological Medicine, 39, 1533-1547. http://dx. doi.org/10.1017/S0033291708004947

Nock, M. K., \& Kazdin, A. E. (2002). Examination of affective, cognitive, and behavioral factors and suicide-related outcomes in children and young adolescents. Journal of Clinical Child \& Adolescent Psychology, 31(1), 48-58. http://dx. doi.org/10.1207/S15374424JCCP3101_07

Snippe, E., Simons, C. P. J., Hartmann, J. A., Menne-Lothmann, C., Kramer, I., Booij, S. H., . . . Wichers, M. (2015). Change in daily life behaviors and depression: Within-person and between-person associations. Health Psychology, 1-9. http://dx.doi.org/10.1037/ hea0000312

Solomon, R. L. (1980). The opponent-process theory of acquired motivation: The costs of pleasure and the benefits of pain. American Psychologist, 35(8), 691-712. http://dx. doi.org/10.1037/0003-066X.35.8.691

StataCorp. (2013). Stata Statistical Software: Release 13. College Station, TX: StataCorp LP.

Taylor, S. (2007). Electroconvulsive Therapy: A Review of History, Patient Selection, Technique, and Medication Management. Southern Medical Journal, 100(5), 494-498. http://dx.doi.org/10.1097/SMJ.0b013e318038fce0

Treadway, M. T., Bossaller, N., Shelton, R. C., \& Zald, D. H. (2012). Effort-Based Decision-Making in Major Depressive Disorder: A Translational Model of Motivational Anhedonia. Journal of Abnormal Psychology, 121(3), 553-558. http://dx. doi.org/10.1037/a0028813 
Treadway, M. T., \& Zald, D. H. (2011). Reconsidering anhedonia in depression: Lessons from translational neuroscience. Neuroscience \& Biobehavioral Reviews, 35(3), 537-555. http://dx.doi.org/10.1016/j.neubiorev.2010.06.006

Trull, T. J., Solhan, M. B., Tragesser, S. L., Jahng, S., Wood, P. K., Piasecki, T. M., \& Watson, D. (2008). Affective instability: Measuring a core feature of borderline personality disorder with ecological momentary assessment. Journal of Abnormal Psychology, 117(3), 647-661. http://dx.doi.org/10.1037/ a0012532

van der Krieke, L., Jeronimus, B. F., Blaauw, F. J., Wanders, R. B. K., Emerencia, A. C., Schenk, H. M., .. Jonge, P. D. (2015). HowNutsAreTheDutch (HoeGekIsNL): A crowdsourcing study of mental symptoms and strengths. International Journal of Methods in Psychiatric Research. http://dx.doi.org/10.1002/mpr.1495

van Roekel, E., Bennik, E. C., Bastiaansen, J. A., Verhagen, M., Ormel, J., Engels, R. C. M. E., \& Oldehinkel, A. J. (2015). Depressive symptoms and the experience of pleasure in daily life: An exploration of associations in early and late adolescence. Journal of Abnormal Child Psychology, 1-11. http://dx.doi.org/10.1007/s10802-015-0090-z

van Roekel, E., Masselink, M., Vrijen, C., Heininga, V. E., Bak, T., Nederhof, E., \& Oldehinkel, A. J. (2016). Study protocol for a randomized controlled trial to explore the effects of personalized lifestyle advices and tandem skydives on pleasure in anhedonic young adults. BMC Psychiatry, 16, 182. http://dx.doi.org/10.1186/s12888016-0880-z
Wang, D. V., \& Tsien, J. Z. (2011). Convergent processing of both positive and negative motivational signals by the VTA dopamine neuronal populations. PLoS ONE, 6(2), e17047. http://dx.doi.org/10.1371/journal.pone.0017047

Weinstock, L. M., Melvin, C., Munroe, M. K., \& Miller, I. W. (2016). Adjunctive Behavioral Activation for the Treatment of Bipolar Depression: A Proof of Concept Trial. Journal of Psychiatric Practice, 22(2), 149-158. http://dx.doi.org/ 10.1097/PRA.0000000000000142

Wichers, M., Simons, C. J. P., Kramer, I. M. A., Hartmann, J. A., Lothmann, C., Myin-Germeys, I., . . . van Os, J. (2011). Momentary assessment technology as a tool to help patients with depression help themselves. Acta Psychiatrica Scandinavica, 124(4), 262-272. http://dx.doi.org/10.1111/j. 1600-0447.2011.01749.x

Wilcox, H. C., \& Anthony, J. C. (2004). Child and adolescent clinical features as forerunners of adult-onset major depressive disorder: Retrospective evidence from an epidemiological sample. Journal of Affective Disorders, 82, 9-20. http://dx. doi.org/10.1016/j.jad.2003.10.007

Wykes, T., Steel, C., Everitt, B., \& Tarrier, N. (2008). Cognitive Behavior Therapy for Schizophrenia: Effect Sizes, Clinical Models, and Methodological Rigor. Schizophrenia Bulletin, 34(3), 523-537. http://dx.doi.org/10.1093/schbul/sbm114

Received: May 2, 2016

ACCEPTED: September 29, 2016

Available online: 8 October 2016 